\title{
In vivo confocal microscopic corneal images in health and disease with an emphasis on extracting features and visual signatures for corneal diseases: a review study
}

\author{
Rania Alzubaidi, ${ }^{1}$ Mhd Saeed Sharif, ${ }^{1}$ Rami Qahwaji, ${ }^{1}$ Stanley Ipson, ${ }^{1}$ Arun Brahma ${ }^{2}$
}

\begin{abstract}
- Additional material is published online only. To view please visit the journal online (http://dx.doi.org/10.1136/ bjophthalmol-2015-306934).

${ }^{1}$ School of Electrical Engineering and Computer Science, University of Bradford, Bradford, UK

${ }^{2}$ Manchester Royal Eye Hospital, Central Manchester University Hospitals NHS Foundation Trust, Manchester Academic Health Science Centre, Manchester, UK

\section{Correspondence to}

Rania Alzubaidi, School of Electrical Engineering and Computer Science, University of Bradford, Richmond Road, Bradford BD7 1DP, UK; raniaalzubaidi@yahoo.com; r.alzubaidi@student.bradford. ac.uk
\end{abstract}

Received 31 March 2015 Revised 6 October 2015 Accepted 15 October 2015 Published Online First 9 November 2015

\section{ABSTRACT}

There is an evolution in the demands of modern ophthalmology from descriptive findings to assessment of cellular-level changes by using in vivo confocal microscopy. Confocal microscopy, by producing greyscale images, enables a microstructural insight into the in vivo cornea in both health and disease, including epithelial changes, stromal degenerative or dystrophic diseases, endothelial pathologies and corneal deposits and infections. Ophthalmologists use acquired confocal corneal images to identify health and disease states and then to diagnose which type of disease is affecting the cornea. This paper presents the main features of the healthy confocal corneal layers and reviews the most common corneal diseases. It identifies the visual signatures of each disease in the affected layer and extracts the main features of this disease in terms of intensity, certain regular shapes with both their size and diffusion, and some specific region of interest. These features will lead towards the development of a complete automatic corneal diagnostic system that predicts abnormalities in the confocal corneal data sets.

\section{INTRODUCTION}

Corneal confocal microscopy is a non-invasive technique for studying the cellular structure of corneal physiology and disease. It offers noninvasive visualisation of the living tissues and provides greyscale images with greatly increased resolutions over light biomicroscopy and biocytology, which both have been very rewarding approaches to improve definitions of disease phenotypes. ${ }^{1}$ This ability to provide high-resolution images of all layers in the living cornea has resulted in new discoveries in corneal pathology at the cellular level ${ }^{2}$ it has been used in the detection and management of pathological and infectious conditions, corneal dystrophies, monitoring contact lens-induced corneal changes and for pre-surgical and post-surgical evaluation following laser vision correction (photorefractive keratectomy, laserassisted in-situ keratomileusis, laser-assisted subepithelial keratectomy). ${ }^{3}$

The normal cornea is avascular, and in histological cross section, it consists of five distinct layers. The corneal epithelium lies at the anterior side and is about $50 \mu \mathrm{m}$ thick at the central corneal region. Bowman's layer is under the epithelium; it is 10 $16 \mu \mathrm{m}$ thick and is acellular except for the nerves that permeate it. The basal lamina of the epithelium is located on Bowman's layer where the latter in turn separates the epithelium from the stroma. The stromal region is about $450 \mu \mathrm{m}$ in thickness and contains large nerves, stromal keratocytes and orthogonal layers of collagen fibres. Descemet's membrane lies posterior to the stroma. It is an acellular layer and about $15-20 \mu \mathrm{m}$ in thickness. The limiting layer on the posterior side of the cornea is a single layer of corneal endothelial cells. ${ }^{4}$

Each corneal disease demonstrates significant qualitative and/or quantitative alterations in the corneal layers in the eyes of patients. In other words, any abnormality occurring in the cornea has its own signs relative to the involved layer. Qualitative changes relate to alterations in the morphology of the corneal layer, while quantitative changes relate to measurements such as cell diameter, cell density, nerve length, total number of nerves within a frame, keratocytes density, number of cells within a frame, corneal reflectivity and corneal thickness. ${ }^{5}$ In vivo confocal microscopy is rapidly becoming a useful method to evaluate the morphological characteristics of corneal abnormalities at the histological level and may be helpful in diagnosis, determination of progression and understanding the pathophysiology of disease. ${ }^{2}$

In ophthalmology, reliable and early diagnosis usually depends on the recognition of minute changes in normal structures. To the patient, the functional consequences of such pathological alterations may be the only aspect of concern; however, ophthalmologists look for morphological criteria that are essential in defining health and disease. ${ }^{1}$ We are working in collaboration with a group of clinical specialists and ophthalmologists to achieve more accurate diagnostics of corneal diseases that will help in developing our vision of an automatic diagnosis system for improving the standards of patient care.

In this paper, we list the most common corneal pathologies, classified according to the International Committee for Classification of Corneal Dystrophies (IC3D classification), and summarise the diagnosis of corneal diseases as they appear in corneal layers with an emphasis on the visual signs of each disease (qualitative changes). We analyse the images as well to extract their features in terms of intensity, region of interest and contained shapes with both their sizes and diffusion.

Our aim is to work towards the development of an automatic corneal diagnostic system that can distinguish between normal and abnormal cornea using the features and the visual signatures that are 
extracted from data sets of corneal images from confocal microscopes.

This paper is organised as follows. In section 'Development of confocal microscopy', the development of confocal microscopy is summarised. In section 'Corneal layers in health', a summary of corneal layers in health is presented. A summary of corneal layers in disease is presented in section 'Corneal layers in disease'. This section displays the most common corneal diseases classified according to the level chiefly affected using the IC3D classification. The final section contains our conclusions and suggestions for future work.

\section{DEVELOPMENT OF CONFOCAL MICROSCOPY}

This review covers many research papers, review papers and case studies from the past two decades that worked with confocal microscope images of the cornea. We include a subsection to cover the history of, and the key people involved in, the development of confocal microscopy. The images in this review were produced by several types of confocal microscopy: tandem scanning confocal microscopy (TSCM), slit scanning confocal microscopy (SSCM) and laser scanning confocal microscopy (LSCM). For that reason, a subsection is included to indicate the differences between these three techniques and what distinguishes each type from the others.

\section{Historical overview of confocal microscopy}

The confocal microscope was originally developed by Marvin Minsky in the mid-1950s. The constructed instrument, which was called the 'double focusing stage scanning microscope', was patented in 1957 and focused the light on a small area of tissue. $^{67}$

The illumination and observation pathways have a common focal point, and because of that this principle is termed 'confocal'.6 After Minsky's work, M. David Egger and Mojmir Petran created a multiple-beam confocal microscope in the late 1960s for examining unstained brain sections and ganglion cells. Egger continued in this arena and developed the first mechanically scanned confocal laser microscope. In 1973, he published the first recognisable images of cells produced by this technique. ${ }^{7}$ Because of the advances in computer and laser technology coupled to new algorithms for digital manipulation of images, during the late 1970s and the 1980s, a growing interest in confocal microscopy developed. ${ }^{7}$

Several investigators translated the practical laser scanning confocal microscope designs into working instrument. Dutch physicist G. Fred Brakenhoff developed a scanning confocal microscope in 1979, while at almost the same time Colin Sheppard contributed to the technique with a theory of image formation. Tony Wilson, Brad Amos and John White nurtured the concept and later (in the late 1980s) demonstrated the utility of confocal imaging in the examination of fluorescent biological specimens. ${ }^{7}$

\section{Types of confocal microscopy}

Tandem scanning confocal microscopy

The first real-time TSCM was developed by Petran and Hadravsky using point illumination and detection. The basic part of the system was modified by Nipkow, who invented a spinning disc composed of sets of conjugate pinholes arranged in spirals. After a specimen is scanned in parallel, a twodimensional image is generated. ${ }^{1} 8$ To eliminate most of the scattered light, the pinholes need to be as small as possible. However, this results in very low light throughput (only $0.25-$ $1 \%$ of light reaches the cornea), which necessitates a high- intensity light source and a low-light-level camera to enable image acquisition. ${ }^{8}$

This original microscope in its clinical version was produced by the Tandem Scanning Corporation (Reston, Virginia, USA) and later by the Advanced Scanning Corporation (New Orleans, Louisiana, USA), and is no longer in production. ${ }^{1}$

\section{Slit scanning confocal microscopy}

An alternative to point scanning, the SSCM was first developed by Thaer for observing the in vivo cornea. This involves illumination from a slit of scanned over the back focal plane of the microscope objective, ${ }^{8}$ which allows all points on the axis of the slit to be scanned at the same time and consequently greatly reduces scanning times over the TSCM. ${ }^{18}$ The slit illumination also allows a greater light throughput than the TSCM and thus a lower intensity light source may be used, allowing longer examination times. ${ }^{8}$ Contrast with the SSCM is greater in comparison to the TSCM, which provides clearer images of the stroma and enables imaging of the low reflecting layer of wing cells in the epithelium. ${ }^{8}$ The slit height may be adjustable, which would allow the user to control the thickness of the optical section and the amount of light throughput. However, the microscope is only truly confocal in the axis perpendicular to the slit and provides lower axial and transverse resolution than the TSCM. ${ }^{18}$

There are commercial sources that provide slit scanning in vivo confocal microscopes such as Tomey Corporation (Cambridge, Massachusetts, USA), Nidek Technologies (Gamagori, Japan) and Helmut Hund (Wetzlar, Germany). ${ }^{1}$

\section{Laser scanning confocal microscopy}

The LSCM was developed by Webb; it employs a coherent laser as a high-intensity light source. The laser beam is scanned using a set of galvanometer scanning mirrors, which provides fast scanning over the xy plane. The reflected light refocused by the microscope objective is rescanned by the galvanometer scanning mirrors and imaged onto a pinhole aperture located in front of a photomultiplier. ${ }^{1}$

One of the well-established in vivo confocal imaging systems used in ophthalmology is the Heidelberg Retina Tomograph (HRT) (Heidelberg Engineering, Heidelberg, Germany). HRT is a device that was designed to acquire and evaluate topographic measurements of the optic nerve head to detect glaucomatous damage using a $670 \mu \mathrm{m}$ diode laser. The University of Rostock (Germany) modified the HRT to use a detachable objective system called the 'Rostock Cornea Module' (RCM). This converts it into a high-resolution LSCM for the visualisation of the anterior segment of the eye. ${ }^{18}$

Optical sections of only a few micrometres can be imaged with a high contrast and precisely measured because of the highdepth resolution. ${ }^{1}$ LSCM provides greater contrast than the TSCM or SSCM. ${ }^{8}$

\section{Performance comparison between different confocal technologies}

Niederer and McGhee ${ }^{8}$ mentioned that limited data are available for comparisons of performance between the different types of in vivo confocal microscopy.

A comparison between keratocyte density measured with TSCM and SSCM (Confoscan 3) demonstrated that, providing the effective depth of the sample volume was taken into consideration, comparable measurements of keratocyte cell density were achievable between the two devices. ${ }^{9}$ 
A further qualitative study compared the SSCM (Confoscan 2) and LSCM (HRT II RCM) appearance of the central cornea in normal subjects and in subjects with corneal dystrophy. The observed morphology was similar with both devices, but image contrast appeared greater with the LSCM. ${ }^{10}$

Endothelial cell density measurement has been compared between SSCM (Confoscan 3) and LSCM (HRT II RCM). All the results of cell density (for patients and normal subjects) that were performed with the RCM were higher than those with the Confoscan 3. ${ }^{11}$

The authors of refs. 812 compared measurements of cell density and image contrast with contemporary SSCM (Confoscan 4, NIDEK, Gamagori, Japan) and LSCM (HRT II RCM). At the levels of the basal epithelium and the endothelium, they observed good agreement between the two devices for cell density measurement. Mid-stromal keratocyte density (measured in cells $/ \mathrm{mm}^{2}$ ) was approximately double with SSCM compared with LSCM, presumably due to differences in optical section thickness. They observed as well that the contrast at the level of the mid-stroma was greater with the LSCM compared with the SSCM and the contrast levels were consistent throughout the image, whereas there was loss of image quality towards the edges of the SSCM image. Poor agreement was observed in measurement of sub-basal nerve plexus (SNP) density, possibly due to differences in image contrast, with values measured with LSCM higher than those measured with SSCM.

A study ${ }^{13}$ observed that SNP density measured with SSCM was two to three times higher than density measured with TSCM.

\section{CORNEAL LAYERS IN HEALTH \\ Epithelium}

Superficial epithelial cells

Superficial epithelial cells present a polygonal cell pattern, reflecting nuclei with bright illuminated cytoplasm, and perinuclear dark halos. In general, the size of the cell is up to $50 \mu \mathrm{m}$ in diameter and about $5 \mu \mathrm{m}$ in thickness (figure 1A). ${ }^{18} 14$ Broadly speaking, superficial epithelial cells have light cell boundaries and bright visible nuclei (figure 1B). ${ }^{15-17}$

\section{Wing cells}

The epithelial intermediate layer (wing cells) forms a regular mosaic with sharp and reflecting cellular borders. The sizes of wing cells (which are regular in form) are about $20 \mu \mathrm{m}$. They can also be subdivided into upper (figure 2A) and lower (figure 2B) wing cells; the latter are smaller. ${ }^{1}{ }^{18}$ These cells,
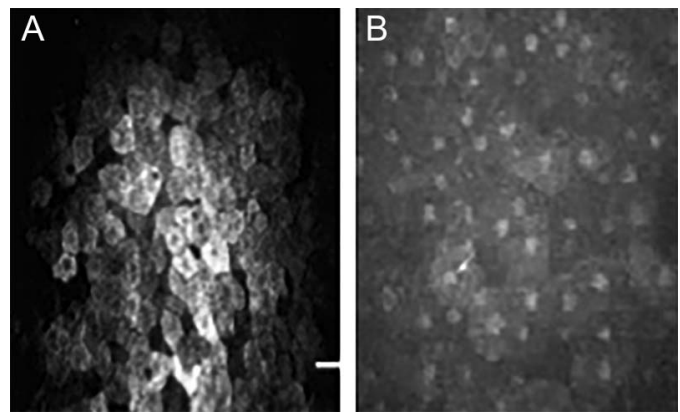

Figure 1 Superficial epithelial cells. (A) Polygonal cell pattern, nucleus with bright illuminated cytoplasm, and perinuclear dark halo Reprinted with permission from Tomii and Kinoshita. ${ }^{14}$ (B) Light cell boundaries and bright visible nuclei (arrow). Reprinted with permission from Jalbert et al. ${ }^{1 \uparrow}$
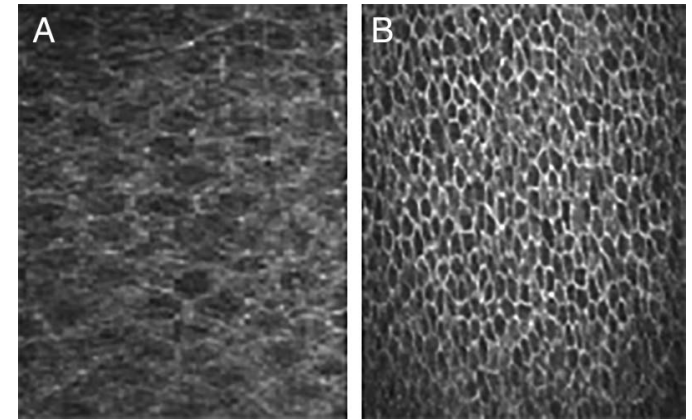

Figure 2 Wing cells. (A) Upper wing cells form a regular mosaic with sharp and reflecting cellular borders' Reprinted with permission from Guthoff et al. ${ }^{1}$ (B) Lower wing cells form a regular mosaic sharp and reflecting cellular borders that are smaller in size than upper cells. Reprinted with permission from Miri et al. ${ }^{18}$

which can probably only be imaged with a scanning slit in vivo confocal microscopy, ${ }^{16}$ are identified by their bright cell borders and a bright cell nucleus, and unlike superficial epithelial cells, have no dark oval ring around the nucleus. ${ }^{8}$ They are characterised by bright cell borders and a bright cell nucleus with few organelles and the nuclei are usually not visible. ${ }^{3}$

\section{Basal epithelial cells}

Basal epithelial cells appear as a regular mosaic of dark cell bodies with light, narrow intercellular reflecting borders and they have a smaller diameter, which is $8-10 \mu \mathrm{m}$ (figure 3), ${ }^{1} 819$ and without nuclei reflectivity such that cells show only cell borders. $^{115} 16$

\section{Sub-basal nerve plexus}

The SNP appears as bright, well-defined long linear nerve fibre bundles, frequently demonstrating branches or anastomosis (figure 4A). ${ }^{8}{ }^{16}{ }^{20}$ It is characterised by the appearance of hyperreflective fibres of lengths that range between 4 and $8 \mu \mathrm{m}$, and organised in a vortex pattern in the lower quadrant of the paracentral cornea (figure 4B). ${ }^{1}{ }^{19}$ SNP may be identified in Bowman's layer. ${ }^{15}$

\section{Bowman's membrane}

Bowman's membrane (anterior limiting lamina) is an acellular hyper-reflective structure, where SNP may be identified. ${ }^{15}{ }^{16}$ It appears as an 'amorphous' layer when viewed with confocal microscopy. ${ }^{8}$ It consists of randomly arranged collagen fibrils located in between the basal cells and the stroma. This cell-free area is $10-16 \mu \mathrm{m}$ in thickness (figure 5). ${ }^{116}$

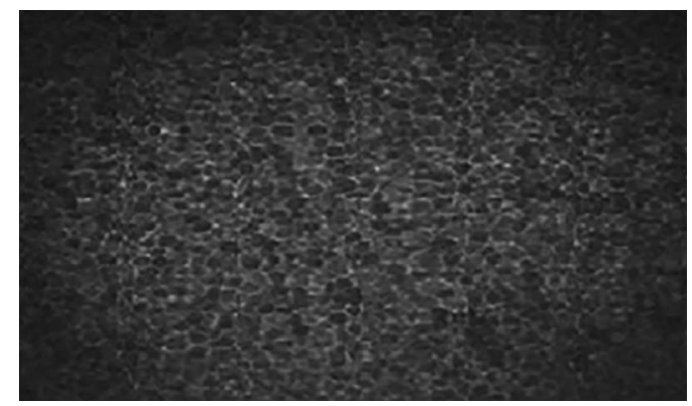

Figure 3 Basal epithelial cells: a regular mosaic of dark cell bodies with light borders without nuclei reflectivity. Reprinted with permission from Petroll and Robertson. ${ }^{19}$ 

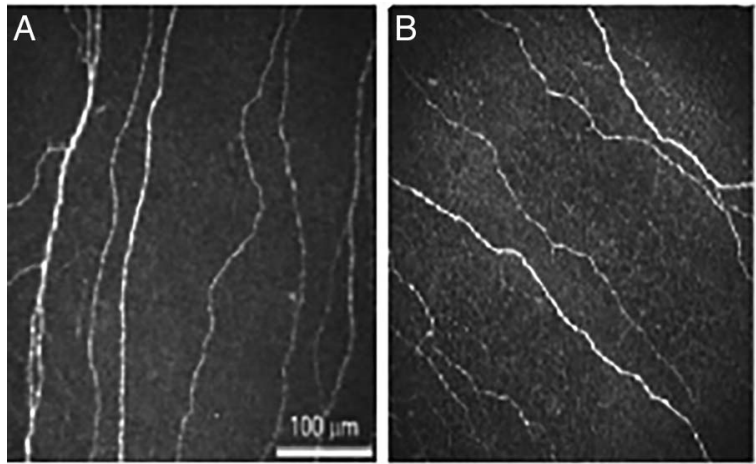

Figure 4 Sub-basal nerve plexus. (A) Bright, well-defined linear long nerve fibre bundles of irregular edges. Reprinted with permission from Patel and McGhee. ${ }^{20}$ (B) The fibres are organised in a vortex pattern in the lower quadrant of the paracentral cornea. Reprinted with permission from Petroll and Robertson. ${ }^{19}$

\section{Stroma}

Corneal stroma forms around $80-90 \%$ of the whole corneal volume. Stromal keratocytes appear as hyper-reflective cell nuclei, typically forming clusters, with poorly visualised cell processes as appeared in figure 6A. The corneal nerves enter the cornea in the mid-stroma and radiate towards the central cornea, dividing into branches (see figure 6B), which are thicker than at the subepithelial level. ${ }^{5} 8151620$ The corneal stroma consists of three main histological components: cellular, acellular and neurosensorial. The connective lamellae appear black (ie, transparent), whereas the keratocyte nuclei are visible as eggshaped light reflecting corpuscles. Using cross-sectional analysis, keratocyte density, which measured in cells $/ \mathrm{mm}^{2}$, is greatest immediately under Bowman's membrane (in the anterior stroma as seen in figure 6C), and it is reported to be around 500-1300 cells $/ \mathrm{mm}^{2}$. The density declines sharply towards the central stroma (minimum 65 cells $/ \mathrm{mm}^{2}$ ), and it increases again slightly in the posterior stroma as seen in figure $6 \mathrm{D}$; it is reported to be around 250-900 cells $/ \mathrm{mm}^{2} \cdot \begin{array}{lllllll}1 & 8 & 15 & 21 & 22 & \text { Keratocyte density }\end{array}$ decreases with age and appears to be independent upon sex. ${ }^{1} 1516$ In ref., 15 it was mentioned that keratocyte density seemed to decrease $0.45 \%$ per year.

\section{Descemet's membrane}

Descemet's membrane is rather difficult to see under normal circumstances and appears as an acellular layer between the posterior stroma and the endothelium. It is usually indiscernible with

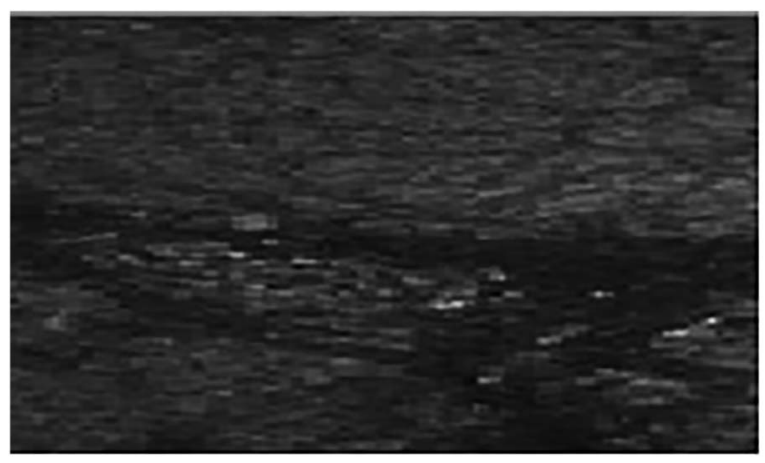

Figure 5 Bowman's membrane: randomly arranged collagen fibrils located in between the basal cells and the stroma' Reprinted with permission from Guthoff et al. ${ }^{1}$
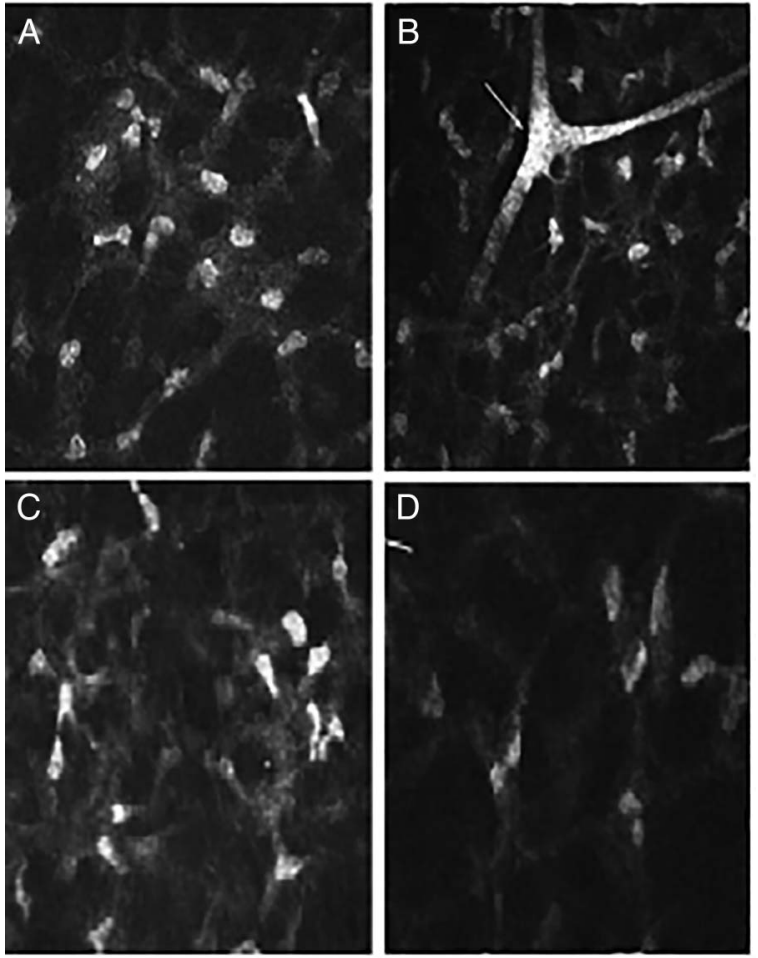

Figure 6 Stroma. (A) Hyper-reflective cell nuclei, typically forming clusters, with poorly visualised cell. Reprinted with permission from Patel and McGhee. ${ }^{5}$ (B) Corneal nerves in the mid-stroma dividing into branches. Reprinted with permission from Patel and McGhee. ${ }^{20}$ (C) Keratocyte density is high in the anterior stroma Reprinted with permission from Miri et al..$^{21}$ (D) Keratocyte density is also high in the posterior stroma. Reprinted with permission from Visser et al. ${ }^{22}$

confocal microscopy, particularly in younger subjects. ${ }^{8} 15$ Also, nerve plexus is not found. ${ }^{15}$ It is thin with thickness about 6-10 $\mu \mathrm{m}^{1}$

\section{Endothelium}

The endothelial cells are located immediately posterior to Descemet's membrane and are characterised by a regular hexagonal hyper-reflective pattern or regular honeycomb mosaic, surrounded by hypo-reflective borders without obvious nuclei reflections (figure 7). ${ }^{1} 81516$ It is easy to recognise this layer because of its clearly identifiable structure. ${ }^{8}$ Sometimes, the nuclei of the cells may be visualised. ${ }^{1}$

\section{CORNEAL LAYERS IN DISEASE}

We use the IC3D Classification of the Corneal Dystrophies, which was introduced in $2008 .^{23}$ Its goal was to develop a new classification system for corneal dystrophies, integrating the most recent information on clinical description, pathological examination and genetic analysis. A template was devised by the IC3D to review the current knowledge of each corneal dystrophy in an organised manner. Each template provides information that includes the name of the dystrophy, alternative names, genetic information (the gene involved and the gene locus of the responsible mutation), onset, signs, symptoms, course, light microscopy, transmission electron microscopy, confocal microscopy and clinical photographs. Each corneal dystrophy is also categorised by the committee based on the level of evidence available to support its existence. The categories are as follows: ${ }^{23}$ 


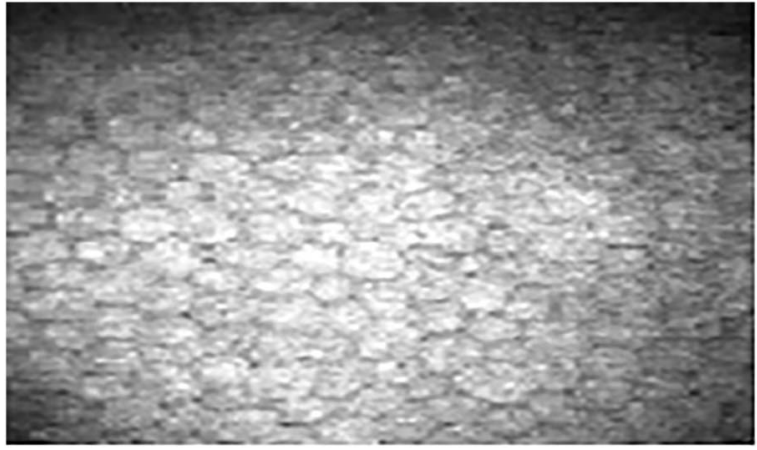

Figure 7 Endothelium: regular hexagonal hyper-reflective pattern of honeycomb regular mosaic surrounded by hyporeflective borders and no found of any nuclei reflection. Reprinted with permission from Tervo and Moilanen. ${ }^{16}$

Category 1: A well-defined corneal dystrophy in which a gene has been mapped and identified and specific mutations are known.

Category 2: A well-defined corneal dystrophy that has been mapped to one or more specific chromosomal loci, but the gene (or genes) remains to be identified.

Category 3: A well-defined corneal dystrophy that has not yet been mapped to a chromosomal locus.

Category 4: This is reserved for suspected new (or previously documented) corneal dystrophies, although the evidence for it, being a distinct entity, is not yet convincing.

The IC3D classification system is organised anatomically according to which corneal layer is affected. In general, it classified dystrophies into four groups: epithelial and subepithelial dystrophies, Bowman layer dystrophies, stromal dystrophies, and Descemet's membrane and endothelial dystrophies. For the purposes of this review article, we will focus only on the organisation that depends on the affected corneal level.

\section{Epithelial and subepithelial}

Amiodarone-induced keratopathy

Amiodarone-induced keratopathy appears in the corneal epithelial cells. It is characterised by bright intracellular, highly reflective inclusions. In more advanced cases, other corneal layers may be involved: bright microdots arise within the anterior and posterior stroma and on the endothelial cell layer. Also, keratocyte density reduces in the anterior stroma. ${ }^{15}$ The basal cell layer from a patient during the period of amiodarone ingestion, clearly showing hyper-reflective cell inclusions, is shown in figure 8A. They are in almost the whole image, except the sides, and appear as white and adjacent small rounded-shape structures (each one forms almost $0.04 \%$ of the image) on highintensity background. During the period of amiodarone ingestion, the anterior stroma as well shows marked increase in the number of microdots distributed almost evenly between nuclei of anterior stroma as seen in figure 8B. ${ }^{24}$ LSCM (HRT II-RCM) was used to capture figure $8 \mathrm{~A}$, B with fields of view $400 \times 400$ pixel.

\section{Advancing wave-like epitheliopathy}

This disease is characterised by the presence of atypical elongated cells with centripetally oriented long axes (needle shape) that are surrounded by a grey hazy halo. There are hyperreflective nuclei on darker grey background at the level of the abnormal epithelium, but confluent hyper-reflective regions are
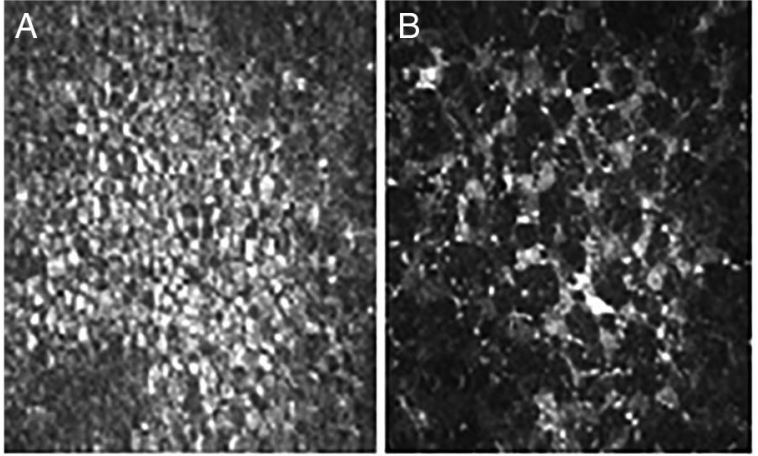

Figure 8 Amiodarone-induced keratopathy. (A) Basal cell layer clearly showing hyper-reflective cell inclusions (laser scanning confocal microscopy (LSCM): Heidelberg Retina Tomograph II Rostock Cornea Module (HRT II-RCM)). (B) Increase in the number of microdots between the keratocyte nuclei in anterior stroma with the period of amiodarone ingestion (LSCM: HRT II-RCM). Reproduced with permission from Falke et al. ${ }^{24}$

demonstrated at the subepithelial level where they appear as hazy reflections. ${ }^{25}$

Epithelial basement membrane dystrophy

Confocal microscopic images for epithelial basement membrane dystrophy reveal four main features. First, highly reflective irregular material, indicated by arrows in figure 9A, intermixed with the keratocytes of the anterior stroma and posterior epithelial interface, and this area is shown as a reflection of medium values in greyscale. Second, the cells of the basal epithelium have abnormal distended cytoplasm with very reflective nuclei that have grey double-walled aureole (the white circle forms $0.4 \%$ of the image), indicated by an arrow in figure 9B. Third, the cysts are elliptic with size of $50-400 \mu \mathrm{m}$, indicated by arrows in figure 9C. The borders of cystic lesions are poorly defined, and there is irregular reflective material within them, as indicated by an asterisk in figure 9C. A basement membrane bearing some long (at least $300 \mu \mathrm{m}$ ), highly reflective, linear structures that have diffuse posterior borders and welldelineated anterior borders are indicated by arrows in figure 9D. A non-reflective space appears within this linear lesion and the normal basement membrane. ${ }^{26}$ SSCM (Confoscan 2) was used to capture figures of epithelial basement membrane dystrophy features with horizontal field width of $610 \mu \mathrm{m}$.

\section{Salzmann's nodular degeneration}

The confocal images of this disease demonstrate adjacent polygonal and irregularly shaped basal epithelial cells with reflective borders and prominent nuclei appearing in each polygonal cell as a small grey dot as shown in figure 10A. Sub-basal nerve fibres exhibit an abnormal pattern with increased thickness and absence of branching as indicated by arrows in figure 10B. The nerve fibre appears as an undulating sloping line with high intensity. Moreover, there is a presence of reflective cellular elements near these fibres. ${ }^{27} 28$ SSCM (Confoscan 2) was used to capture the images of Salzmann's nodular degeneration.

\section{Gelatinous drop-like dystrophy}

The epithelial cells of gelatinous drop-like dystrophy are hyperreflective adjacent polygonal shapes with irregular structure and often elongated as shown in figure 11A. At the level of the Bowman's membrane in figure $11 \mathrm{~B}$, a very small number of sub- 

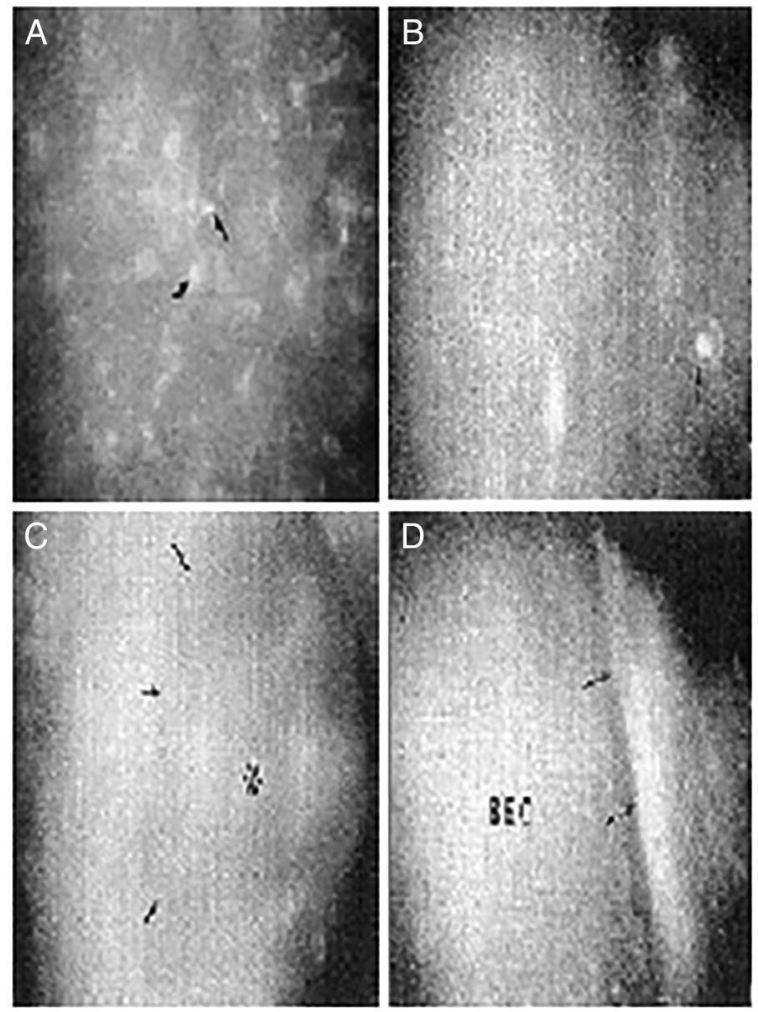

Figure 9 Epithelial basement membrane dystrophy. (A) Highly reflective irregular material (arrows) intermixed with the keratocytes of the anterior stroma and posterior epithelial interface (slit scanning confocal microscopy (SSCM): Confoscan 2). (B) Abnormal distended cytoplasm with very reflective nuclei (arrow) in the basal epithelium (SSCM: Confoscan 2). (C) Elliptic cysts (arrows) with poorly defined of borders, and there is irregular reflective material within them (asterisk) (SSCM: Confoscan 2). (D) Long highly reflective and linear structures (arrows) that have diffuse posterior borders and well-delineated anterior borders (SSCM: Confoscan 2). Reproduced with permission from (Hernandez-Quintela et al. ${ }^{26}$

basal nerves with increased background intensity can be seen. We can notice as well some highly reflective small dots spread over the image (each forms $0.08 \%$ of the image). Figure $11 \mathrm{C}$ shows large accumulations of brightly reflective amyloid
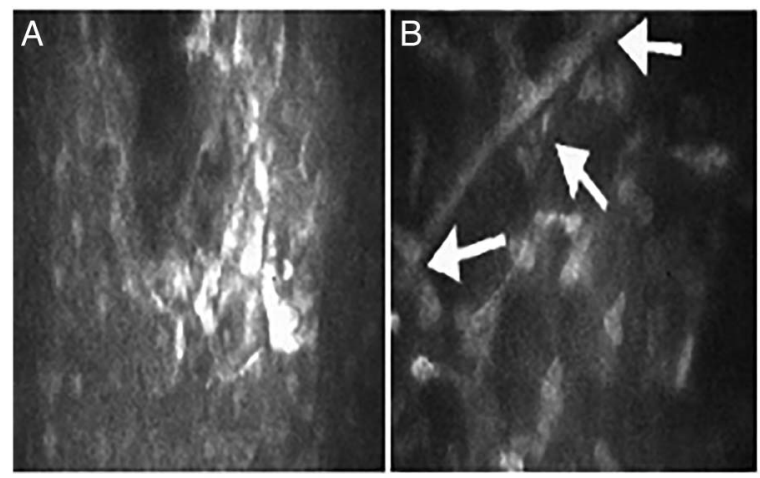

Figure 10 Salzmann's nodular degeneration. (A) Large cells with prominent nuclei and bright margins are present in the superficial layer of the central corneal epithelium (slit scanning confocal microscopy (SSCM): Confoscan 2). (B) An abnormally thick sub-basal corneal nerve (arrows) is surrounded by highly reflective cells (SSCM: Confoscan 2). Reproduced with permission from Ku et al. ${ }^{27}$ materials beneath the epithelium and within the anterior stroma. Also, the nuclei of keratocytes were poorly identifiable. ${ }^{29}$ LSCM (HRT II-RCM) with field of view $400 \times 400$ pixel was used to capture the images of gelatinous drop-like dystrophy.

\section{Thygeson epithelial keratitis}

Thygeson keratitis shows highly reflective deposits (50-300 $\mu \mathrm{m}$ in diameter) with cotton-like appearance in the basal epithelial cell layer and Bowman's layer (see figure 12A). These cotton-like deposits accumulate in the middle of the image. Highly reflective material appears in figure $12 \mathrm{~B}$ that directly damages epithelial cell connection while epithelial cells are swelling and losing polygonal structure, and cell gaps are widening as well. In other words, epithelial cells look like cracked ground. These cells are disconnected and appear as high-intensity curvy lines on lowintensity background. ${ }^{30-33}$ LSCM (HRT II-RCM) with field of view $400 \times 400 \mu \mathrm{m}$ was used to capture figure $12 \mathrm{~A}, \mathrm{~B}$.

\section{Meesmann's dystrophy}

The cystic lesions in this disease, which are $10-50 \mu \mathrm{m}$ in diameter, appear in round, well-delineated shapes surrounded by reflective points in the cytoplasm, which probably correspond to cell nuclei, as indicated by arrows in figure 13A. Above an apparently normal basal membrane, some normal cell nuclei appear as reflective round regions, as indicated by arrowheads in figure $13 \mathrm{~A} .{ }^{26}$ Multiple cyst-like changes are seen at the level of the basal epithelium in figure $13 \mathrm{~B}$. They are very similar in size (each forms 3\% of the image) and are distributed non-uniformly
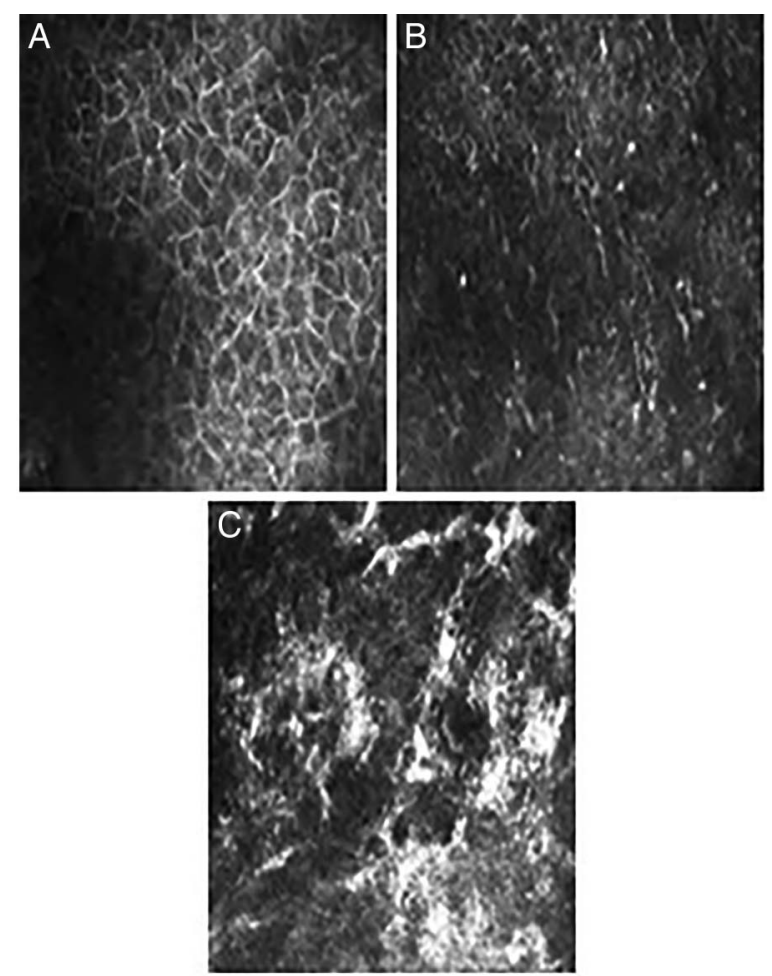

Figure 11 Gelatinous drop-like dystrophy. (A) The epithelial cells are irregular in shape and often elongated (laser scanning confocal microscopy (LSCM): Heidelberg Retina Tomograph II Rostock Cornea Module (HRT II-RCM)). (B) At the level of the Bowman's membrane, a very small number of sub-basal nerves (LSCM: HRT II-RCM). (C) Large accumulations of brightly reflective amyloid materials within the anterior stroma (LSCM: HRT II-RCM), with permission from Jing et al. ${ }^{29}$ 

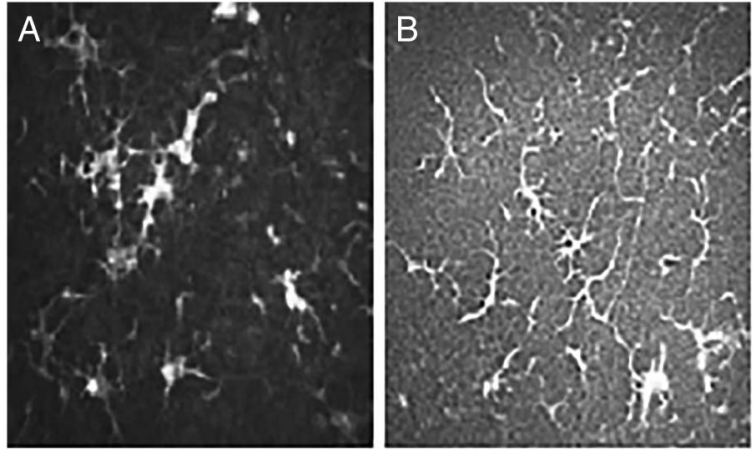

Figure 12 Thygeson epithelial keratitis. (A) At the basal epithelial cell layer, aggregates of highly reflective deposits that had a cotton-like appearance (Laser scanning confocal microscopy, LSCM: Heidelberg Retina Tomograph II Rostock Cornea Module (HRT II-RCM)). Reproduced with permission from Steger et $a^{32}$. (B) Invasion of numerous material with highly reflective dendritic structure, and epithelial cells were swelling and cell gaps were widened (LSCM: HRT II-RCM). Reproduced with permission from Steger et al. ${ }^{33}$

with white colour while the normal cells have very dark grey colour with unclear borders. ${ }^{8}$ Figure $13 \mathrm{~A}$ was captured by SSCM (Confoscan 2) with horizontal field width of $610 \mu \mathrm{m}$, while figure 13B was captured by LSCM (HRT II-RCM) with field of view $400 \times 400$ pixel.

\section{Recurrent erosion syndrome}

In figure 14, superficial polygonal low reflective areas are seen surrounded by bright epithelial cells, and a mucus band appears as a bright line over the epithelial mosaic. The length of each line is approximately equal to the horizontal field width of the image, which is $610 \mu \mathrm{m}$. SSCM (Confoscan 2) was used to obtain this figure. No epithelial cystic lesions are found by confocal microscopy. ${ }^{26}$

\section{Acanthamoeba infective keratitis}

Acanthamoeba cysts and trophozoites have a typical structure that allows rapid diagnosis leading to early institution of treatment. The cysts appear as highly reflective, round-shaped
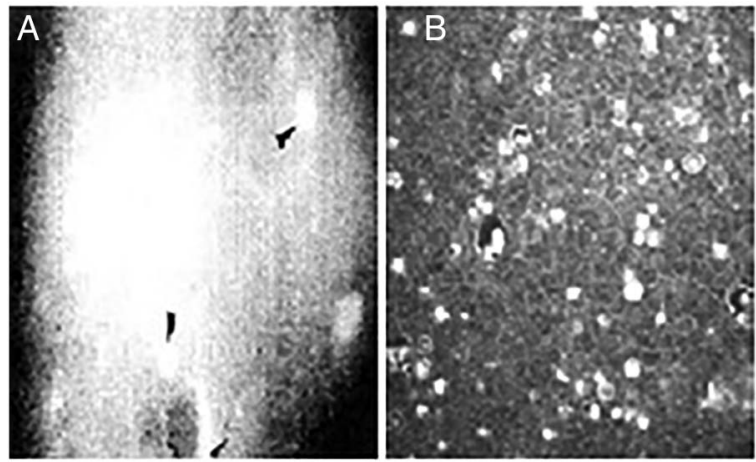

Figure 13 Meesmann's dystrophy. (A) Round shape and well-delineated lesions that are surrounded by reflective points in the cytoplasm, which probably correspond to cell nuclei (arrows), some normal cell nuclei appear as reflective round images (arrowheads) (slit scanning confocal microscopy: Confoscan 2). Reproduced with permission from Hernandez-Quintela et al. ${ }^{26}$ (B) Cyst-like changes at the level of the basal epithelium (laser scanning confocal microscopy: Heidelberg Retina Tomograph II Rostock Cornea Module). Reproduced with permission from Niederer and McGhee. ${ }^{8}$

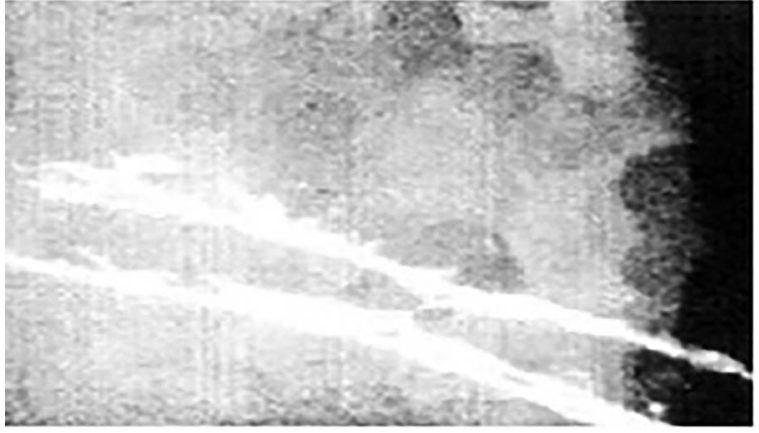

Figure 14 Recurrent erosion syndrome: a mucus band appears as a bright line over the epithelial mosaic (slit scanning confocal microscopy: Confoscan 2). Reproduced with permission from Hernandez-Quintela et al. ${ }^{26}$

particles (10-20 $\mu \mathrm{m}$ in diameter) or ovoid structures, ranging in diameter from 10 to $26 \mu \mathrm{m}$ within the corneal epithelium and stroma. It is possible to find cysts as single-walled structures, as appeared in figure $15 \mathrm{~A}$, or conglomerates with double-walled structures, as indicated by arrows in figure 15B. ${ }^{1} 8 \quad 16 \quad 34-36$ Figure 15A was captured by LSCM (HRT II-RCM) with field of view $400 \times 400 \mu \mathrm{m}$, and TSCM was used to capture figure $15 \mathrm{~B}$ with field of view $475 \times 350 \mu \mathrm{m}$.

\section{Bacterial keratitis}

Confocal microscope images of bacterial keratitis show typical hyper-reflective defects without recognisable structure, as indicated in figure 16A. The adjacent epithelium is oedematous. ${ }^{1}$ Bacterial keratitis is demonstrated as either distinct needle-like deposits or amorphous deposits at different epithelial depths as shown in figure 16B. ${ }^{8} 37$ An increased density of dendritic-like inflammatory cells within the epithelium, shown in figure $16 \mathrm{C}$, has also been reported in a patient with bacterial keratitis. ${ }^{8} 36$ The study of ref. ${ }^{38}$ used confocal microscopy to identify Nocardia, which are filamentous bacteria. The confocal scan of Nocardia in this study revealed multiple, thin and short filamentous structures that demonstrated right-angled branching within the epithelium as indicated by white arrow in figure $16 \mathrm{D}$. These filamentous structures were surrounded by
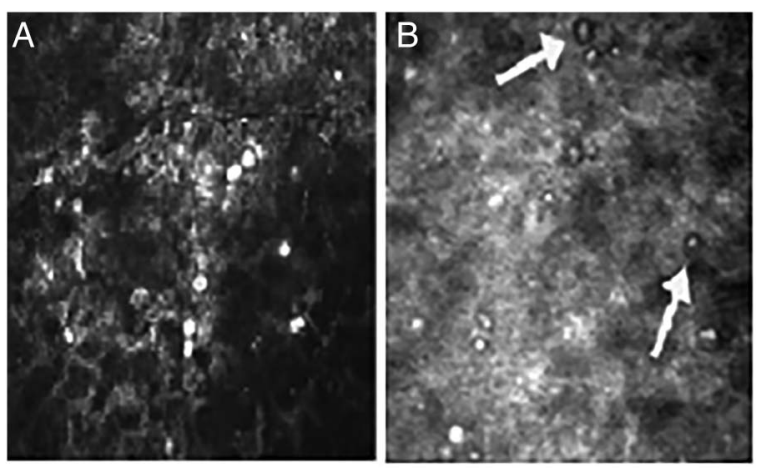

Figure 15 Acanthamoeba infective keratitis. (A) Hyper-reflective single-walled, round-shaped or ovoid cysts within the corneal epithelium and stroma (laser scanning confocal microscopy: Heidelberg Retina Tomograph II Rostock Cornea Module). Reproduced with permission from Labbe et al. ${ }^{36}$ (B) Bright double-walled, round-shaped or oval particles (arrows) are observed in the surrounding epithelium (tandem scanning confocal microscopy). Reproduced with permission from Tervo and Moilanen. ${ }^{16}$ 

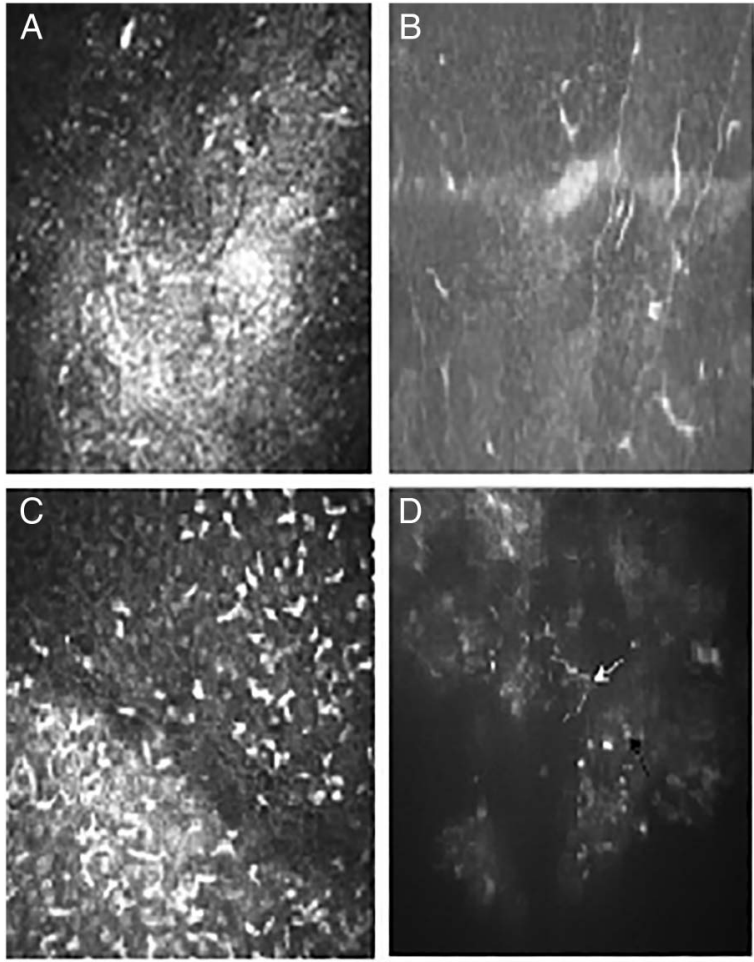

Figure 16 Bacterial keratitis. (A) Typical hyper-reflective defects without recognisable structure (laser scanning confocal microscopy (LSCM): Heidelberg Retina Tomograph II Rostock Cornea Module (HRT II-RCM)). Reproduced with permission from Guthoff et al. ${ }^{1}$ (B) Distinct needle-like deposits or amorphous deposits at different epithelial depths (LSCM: HRT II-RCM). Reproduced with permission from Müller et al. ${ }^{37}$ (C) Increased density of hyper-reflective dendritic-like inflammatory cells within the epithelium (LSCM: HRT II-RCM). Reproduced with permission from Labbe et al. ${ }^{36}$ (D) Thin and short filamentous structures demonstrating right-angled branching within the epithelium (white arrow), surrounded by round to oval bright inflammatory cells (black arrow) (slit scanning confocal microscopy: Confoscan 3). Reproduced with permission from Vaddavalli et al. ${ }^{38}$

round to oval bright structures that represent inflammatory cell infiltration as indicated by black arrow in figure $16 \mathrm{D}$. Figure 16A-C were taken by LSCM (HRT II-RCM) with field of view $400 \times 400 \mu \mathrm{m}$, while figure $16 \mathrm{D}$ was taken by SSCM (Confoscan 3).

Viral keratitis: herpes simplex virus

Herpes simplex virus (HSV) infection is usually followed by an inflammatory response, which can seriously damage all corneal layers. ${ }^{39}$ A classification scheme has been proposed for HSV keratitis: ${ }^{39} 40$ infectious epithelial keratitis, neurotrophic keratopathy, herpetic stromal keratitis and endotheliitis. Superficial epithelium layer shows, as indicated in figure 17A, increase in cell size and hyper-reflectivity while there is a decrease in cell density. ${ }^{39}$ In HSV endothelitis, ${ }^{40}$ pseudoguttata look alike true corneal guttata but are less regularly shaped. As indicated by single arrows in figure $17 \mathrm{~B}$, instead of a round white dot in the centre, they possess a line of high reflection on the border of the elevated dark area. Intercellular gaps are characterised by small black dots at the vertices of endothelial cells and by pronounced intercellular borders as shown in figure $17 \mathrm{~B}$ by double arrows. Some patients with HSV infection have alterations of the SNP. Other patients have no visible sub-basal nerve or
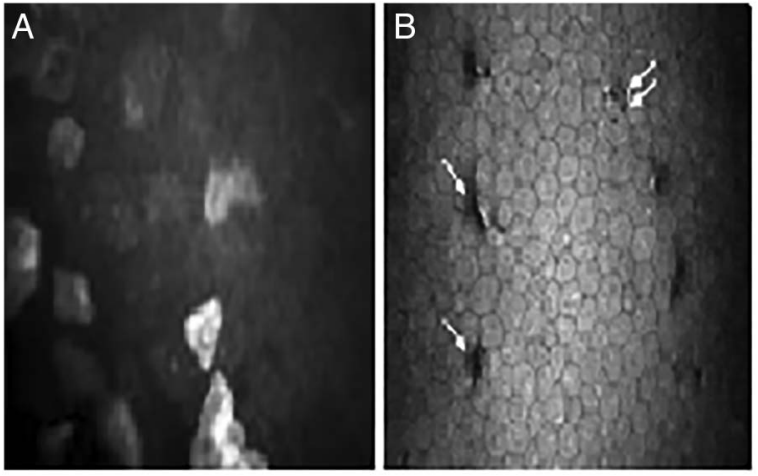

Figure 17 Viral keratitis: herpes simplex virus. (A) Increase in cell size and hyper-reflectivity while there is a decrease in cell density (slit scanning confocal microscopy (SSCM): Confoscan 4). Reproduced with permission from Hamrah et al. ${ }^{39}$ (B) Pseudoguttata possess a line of high reflection on the border of the elevated dark area (single arrows), and intercellular gaps appear as small black dots at the vertices of endothelial cells (double arrows) (SSCM: Confoscan 3). Reproduced with permission from Hillenaar et al. ${ }^{40}$

reduced nerve density. ${ }^{8}{ }^{41}$ An SSCM (Confoscan 4) with field of view $460 \times 345 \mu \mathrm{m}$ was used to take figure $17 \mathrm{~A}$, while figure $17 \mathrm{~B}$ was captured by SSCM (Confoscan 3) with field of view $425 \times 320 \mu \mathrm{m}$.

For easier reference to the appearance of epithelial and subepithelial diseases, we summarise the visual signature of each disease in online supplementary appendix table A1.

\section{Bowman's layer}

Reis-Bückler's dystrophy

Images of patients with Reis-Bückler's dystrophy show focal deposition of homogeneous, reflective material, as indicated by arrows in figure 18A, interspersed with the basal epithelial cells. This image shows medium-intensity branching and undulating lines in the middle on a hazy background. In the left of the image, there is an elongated reflective area that has many values of intensity in greyscale; the outside boundary is dark grey, and the inner side near the boundary is grey and the middle is light grey that approximates to values of white. The region of interest (which forms 20\% of the image) is located in the right side (almost starts from the centre right and extends to the right top); it is a high-intensity area (arrows in the figure) with grey boundary that is interspersed with the basal epithelial cells. Highly reflective material at the level of Bowman's layer is indicated by an asterisk in figure $18 \mathrm{~B}$. This reflective area covers almost the whole image except the sides. Boundaries of the reflective area have lower intensity. We can notice as well a lowintensity patch in the centre left, which forms $2 \%$ of the image and another two patches in the right centre and in the top centre (each forms $0.3 \%$ of the image). In figure 18C, showing the anterior stroma, ${ }^{42}$ asterisk indicates fine diffuse deposits interspersed between keratocyte nuclei, which are indicated by arrows.

Another study demonstrates the presence of focal highly reflective and large number of adjacent irregular and granular materials (on average each material forms $0.2 \%$ of the image) without dark shadows in the basal epithelial layer, shown in figure 18D. At the level of Bowman's layer, there is highly reflective small granular material actually replacing Bowman's layer shown in figure $18 \mathrm{E} .{ }^{43}$ SSCM (Confoscan 4) with field of 

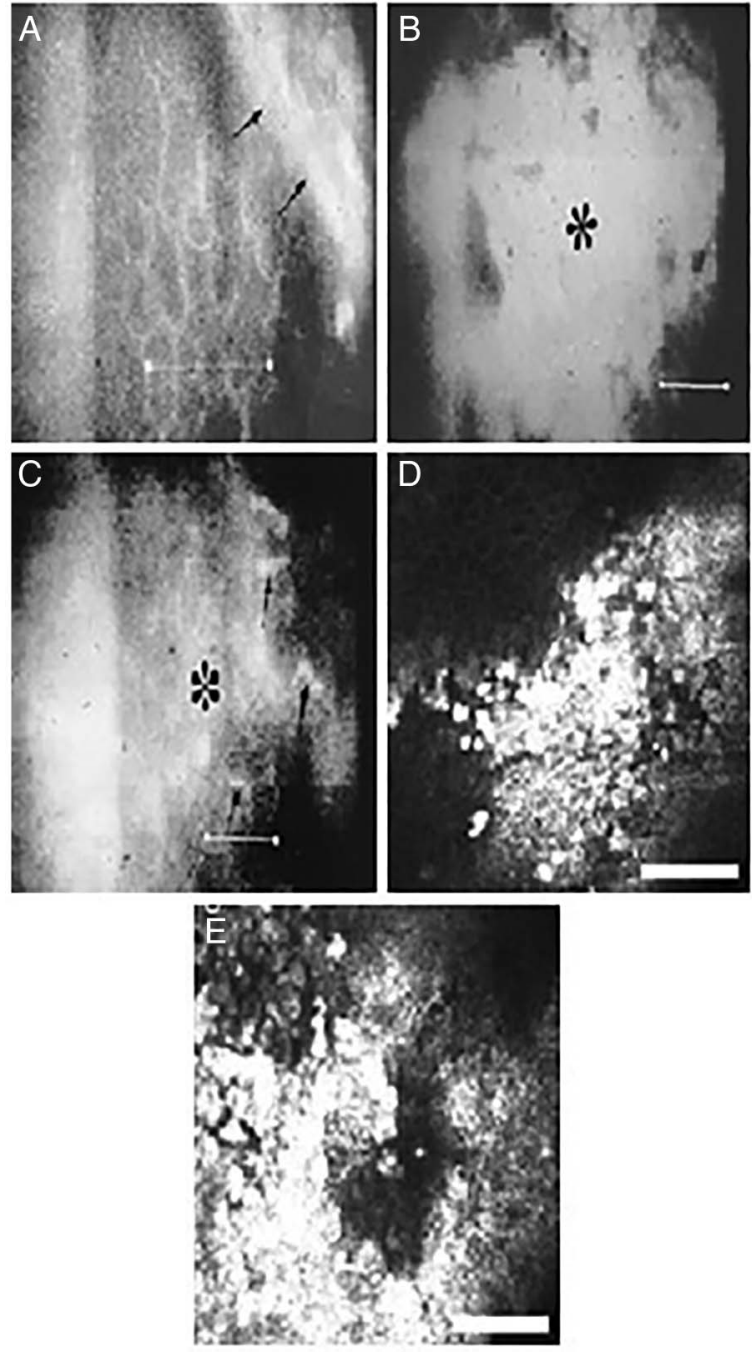

Figure 18 Reis-Bückler's dystrophy. (A) Deposition of homogeneous, reflective material (arrows) interspersed with the basal epithelial cells (slit scanning confocal microscopy (SSCM): Confoscan 4). (B) Highly reflective material (asterisk) at the level of Bowman's layer (SSCM: Confoscan 4). (C) Fine diffuse deposits (asterisk) interspersed between keratocyte nuclei (arrows) in the anterior stroma (SSCM: Confoscan 4). Reproduced with permission from Werner et al. ${ }^{42}$ (D) Deposition of highly reflective irregular and granular materials without dark shadows in the basal epithelial layer (laser scanning confocal microscopy (LSCM)). (E) High reflective small granular materials replaced Bowman's layer (LSCM). Reproduced with permission from Kobayashi and Sugiyama. $^{43}$

view $767 \times 575$ pixel was used to take figure $18 \mathrm{~A}-\mathrm{C}$, while figure $18 \mathrm{D}$, E were captured by LSCM with field of view $400 \times 400$ pixel.

\section{Thiel-Behnke dystrophy}

This disease shows the presence of deposits with homogenous reflectivity, rounded edges and dark shadows in the basal epithelium, as indicated in figure 19A. We see these deposits appear as haze of different intensity values in the right third of the image and also in the left third. In the central third, the basal epithelial cells appear clearly with hyporeflective borders. The edges that separate these three parts have a very low-intensity undulating structure but at the level of Bowman's layer. This homogeneous reflective material appears as haze with different values of
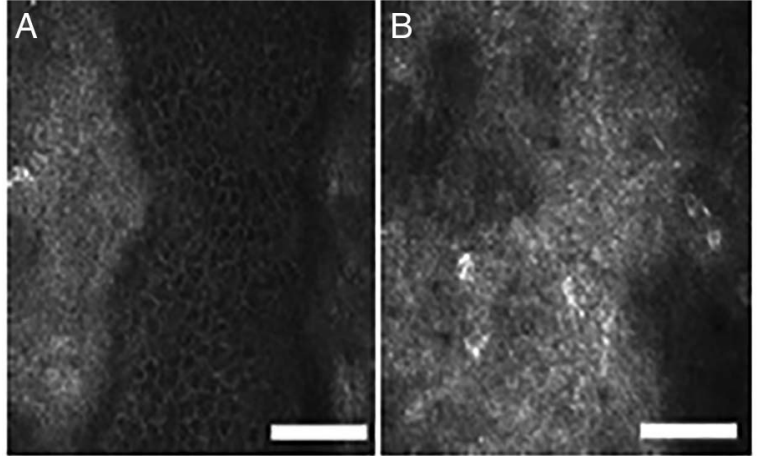

Figure 19 Thiel-Behnke dystrophy. (A) Deposits with homogenous reflectivity, rounded edges and dark shadows in the basal epithelium (laser scanning confocal microscopy (LSCM)). (B) The homogeneous reflective materials completely replaced Bowman's layer (LSCM). Reproduced with permission from Kobayashi and Sugiyama. ${ }^{43}$

intensity and there are some diffuse bright irregular spots (each forms on average $0.3 \%$ of the image). Bowman's layer is completely replaced as indicated in figure $19 \mathrm{~B} .{ }^{8}{ }^{43}$ LSCM with field of view $400 \times 400$ pixel was used to take Thiel-Behnke dystrophy images.

For easier reference to the appearance of Bowman layer diseases, we summarise the visual signature of each disease in online supplementary appendix table A2.

\section{Stromal}

Lattice dystrophy

In figure 20A, confocal microscopy reveals the presence in the mid-stroma of unspecified, undulating and thinner string-like structures as indicated by arrows, apparently interacting with the keratocytes. ${ }^{44-46}$ Also, highly reflective deposits, which are indicated by arrows, are observed in figure 20B under the basal epithelial cells. In figure 20C, immediately under the basal cells of the epithelium, Bowman's layer is seen to be irregular in thickness, demonstrated as differences in greyscale, which are indicated by arrows. This may be due to accumulation of amyloid. $^{45} 46$ Poorly demarcated, hyper-reflective, linear and branching structures of varying intensity are the main characteristics of amyloid deposition in lattice dystrophy shown in figure $20 \mathrm{D}^{8}$ LSCM (HRT II-RCM) with field of view $400 \times 400$ pixel was used to produce figure 20A-D.

A study on lattice dystrophy ${ }^{42}$ revealed reflective punctiform structures in the basal epithelial cell layer, indicated as arrows in figure 20E. In figure $20 \mathrm{~F}$ in the anterior stroma, fine, diffuse, reflective deposits (indicated by asterisk) are interspersed between keratocyte nuclei (indicated by arrows). In figure 20G, showing the anterior and middle stroma, tubular structure filaments with well-defined edges are indicated by arrowheads interspersed with normal keratocytes indicated by arrows. SSCM (Confoscan 4) with field of view $767 \times 575$ pixel was used to take figure $20 \mathrm{E}-\mathrm{G}$.

\section{Fleck dystrophy}

In fleck dystrophy, hyper-reflective and largely intracellular dots with various shapes are distributed throughout the corneal stroma. $^{8} 1547$ They consist of spherical matter with diameters of $3-5 \mu \mathrm{m}$ and are sometimes enclosed in cyst-like structures as indicated in figure 21 , which was taken by SSCM. ${ }^{15} 47$ 

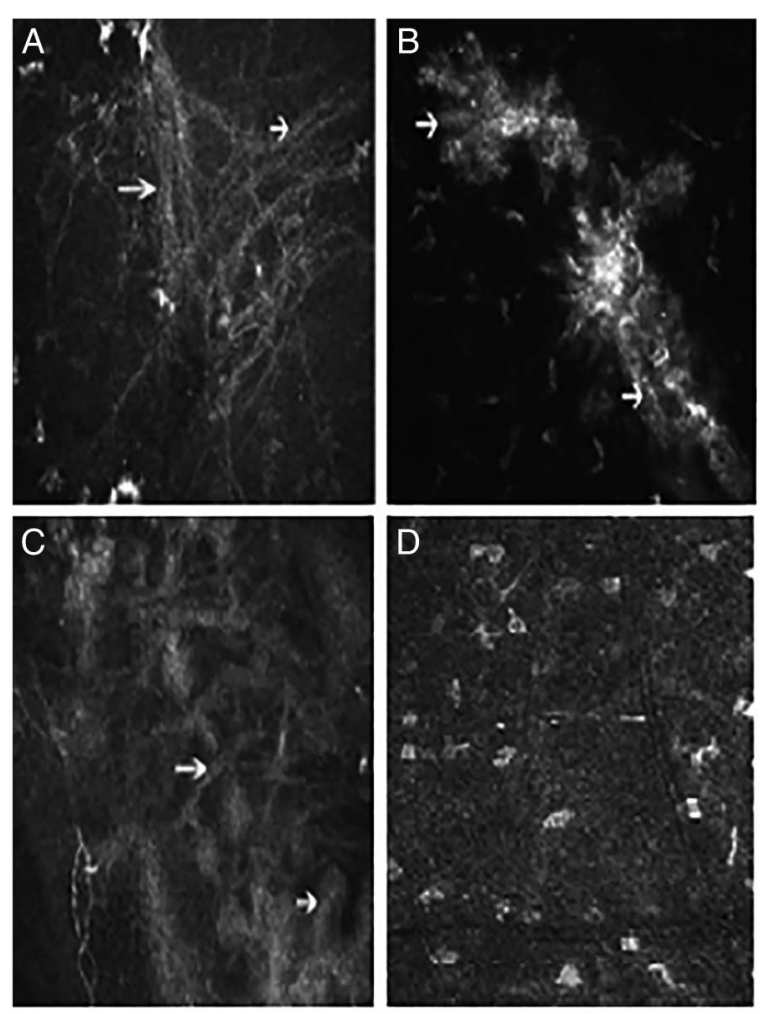

Figure 20 Lattice dystrophy. (A) Unspecified undulating and thinner structures (arrows), apparently interacting with the keratocytes in the mid-stroma (laser scanning confocal microscopy (LSCM): Heidelberg Retina Tomograph II Rostock Cornea Module (HRT II-RCM)). (B) Highly reflective deposits (arrows) under the basal epithelial cells (LSCM: HRT II-RCM). (C) Bowman's layer is irregular and thicker, seen as differences in greyscale (arrows) (LSCM: HRT II-RCM). Reproduced with permission from (Kailasanathan and Maharajan. ${ }^{46}$ (D) Poorly demarcated, hyper-reflective, linear and branching structures of varying intensity for amyloid deposition (LSCM: HRT II-RCM). Reproduced with permission from Niederer and McGhee. ${ }^{8}$ (E) Reflective punctiform structures (arrows) in the basal epithelial cell layer (slit scanning confocal microscopy (SSCM): Confoscan 4). (F) Diffuse, reflective deposits (asterisk) interspersed between keratocyte nuclei (arrows) in the anterior stroma (SSCM: Confoscan 4). (G) Filaments with well-defined edges (arrowheads) interspersed with normal keratocytes (arrows) in the anterior and middle stroma (SSCM: Confoscan 4). Reproduced with permission from Werner et al. ${ }^{42}$

\section{Granular dystrophy}

In granular dystrophy confocal images, hyper-reflective breadcrumb-like deposits measuring approximately $50 \mu \mathrm{m}$ in diameter are observed in the basal epithelial cell layer, as indicated by arrows in figure 22A. In the anterior stroma near the Bowman layer region, reflective diffuse deposits are noticeable in figure 22B (indicated by arrows). A nerve fibre without myelin appears as a bright line (indicated by arrowhead) in figure $22 \mathrm{~B}$. In the deep stroma, shown in figure 22C, keratocyte nuclei are indicated by arrows interspersed with punctiform reflective deposits, which are indicated by arrowheads. ${ }^{42}$ SSCM (Confoscan 4 ) with field of view $767 \times 575$ pixel was used to obtain figure 22A-C.

\section{Avellino corneal dystrophy}

In the basal epithelial of an Avellino corneal dystrophy patient, focal deposits of highly reflective granular materials without dark shadows are observed (see figure 23A). At the level of the
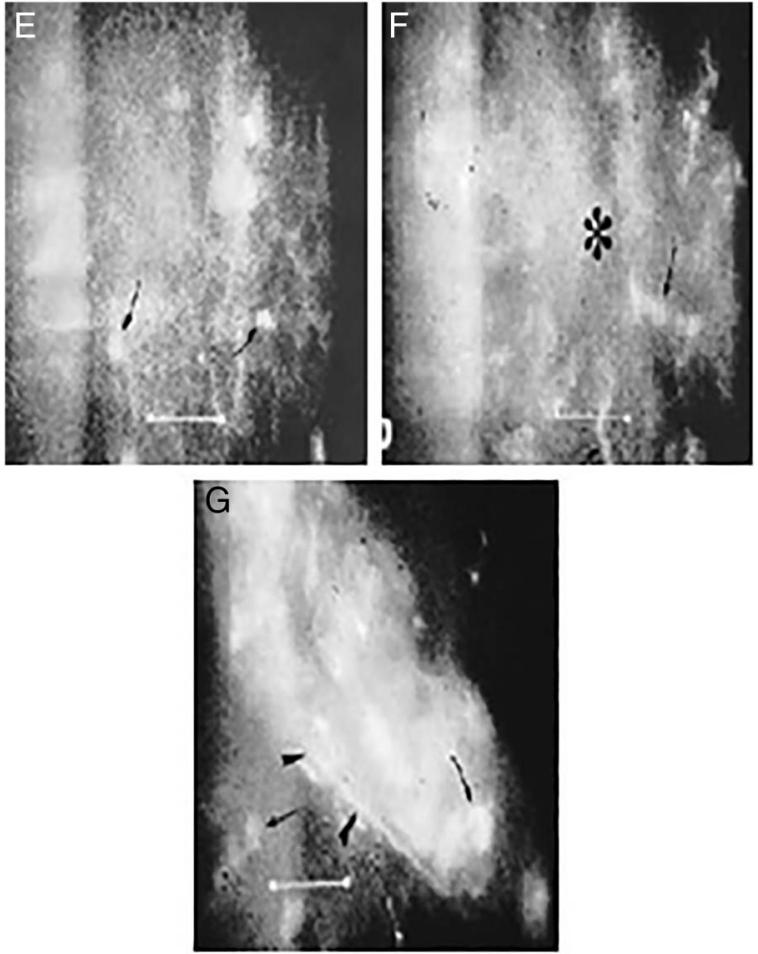

Figure 20 Continued.

superficial and middle stroma, figure 23B shows clusters of highly reflective granular materials with irregular edges. ${ }^{48} 49$ The images of Avellino corneal dystrophy were captured by SSCM (Confoscan 4).

Schnyder crystalline corneal dystrophy

A study analysing the corneal morphology in Schnyder dystrophy demonstrated that highly reflective elliptic material, presumably cholesterol or lipid, accumulates inside and around anterior keratocytes, which have hyporeflective irregular structure, indicated by arrows in figure 24A. Also, brightly reflective punctiform deposits indicated by arrows in figure $24 \mathrm{~B}$ are associated with the subepithelial nerves. Figure 24A, B were captured by a TSCM (model 165A) with field of view $450 \times 360 \mu \mathrm{m}$, and each image was cropped to $250 \times 170 \mu \mathrm{m}$. Moreover, crystalline needleshaped adjacent deposits appear in the anterior stroma, ${ }^{50}$ and the crystals are needle shaped as shown in figure $24 \mathrm{C}$, or rectangular. ${ }^{51}$

Another study shows that, at the level of Bowman's layer, a small number of subepithelial nerves are detectable with high background intensity in figure $24 \mathrm{D}$, but in other cases these nerves are undetectable. ${ }^{51}$ LSCM with field of view $400 \times 400$ pixel was used to take figure $24 \mathrm{C}$, D.

The study of Schnyder dystrophy ${ }^{52}$ confirms the presence of large or multiple deposits of brightly reflective crystalline material extending from the anterior to the mid-stroma. Some abnormal nerve branches with an irregularly curved appearance are also found in the anterior stroma as shown in figure $24 \mathrm{E}$, which was taken by SSCM (Confoscan 2). The subepithelial nerve plexus are undetectable.

Macular corneal dystrophy

In the superficial stroma of macular corneal dystrophy as indicated by an asterisk in figure $25 \mathrm{~A}$, we can see highly reflective deposits without distinct borders. Figure 25B shows the middle 


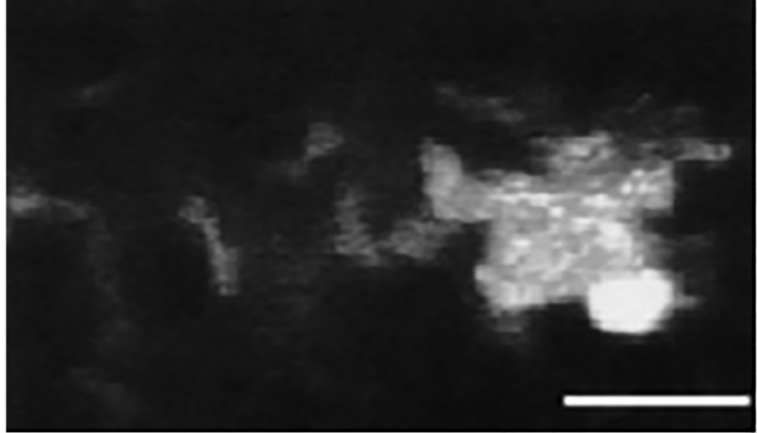

Figure 21 Fleck dystrophy: hyper-reflective and largely intracellular dots distributed throughout stroma, and a cluster of these hyper-reflective dots enclosed in cyst-like structures (slit scanning confocal microscopy). Reproduced with permission from Chiou et al. ${ }^{15}$

stroma containing homogeneous reflective materials with dark striae-like features as indicated by an arrow. ${ }^{48} 53$ LSCM (HRT II-RCM) was used to capture the images of macular corneal dystrophy.

Central cloudy dystrophy of François

This disease reveals small highly reflective granules and deposits in the superficial stromal layer. In the deep stroma adjacent to the corneal endothelial layer, multiple dark acellular striae
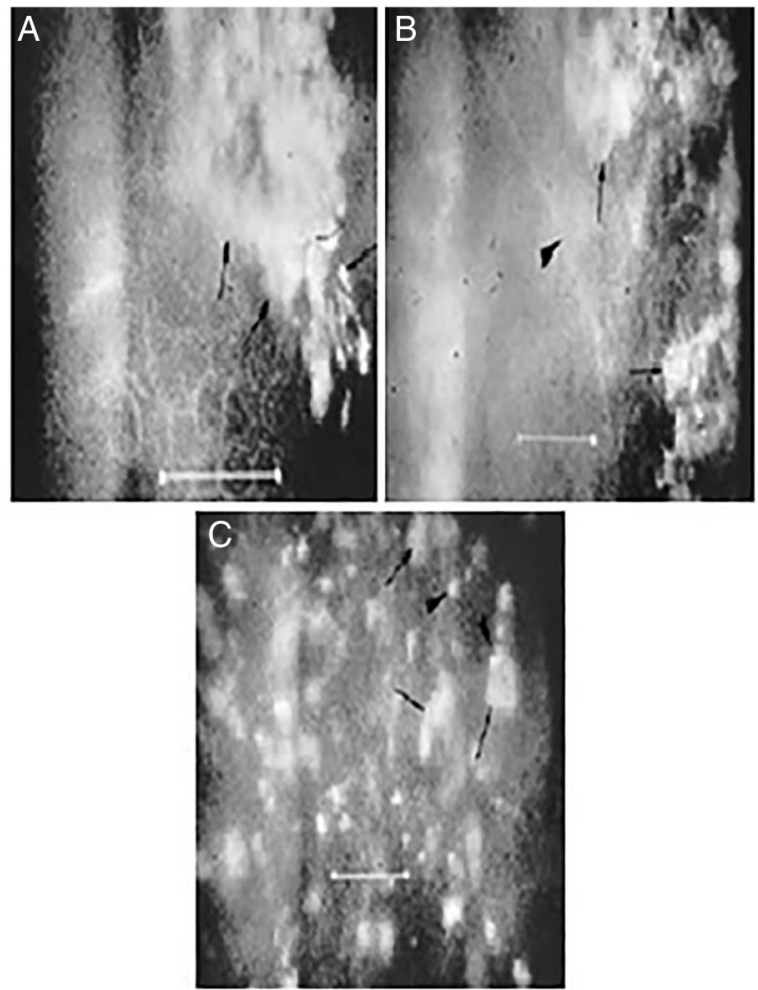

Figure 22 Granular dystrophy. (A) Hyper-reflective breadcrumb-like deposits in the basal epithelial cell layer (arrows) (slit scanning confocal microscopy (SSCM): Confoscan 4). (B) Reflective diffuse deposits (arrows) in the anterior stroma near the Bowman layer region, and a nerve fibre without myelin appears as a bright line (arrowhead) (SSCM: Confoscan 4). (C) Keratocyte nuclei (arrows) interspersed with punctiform reflective deposits (arrowheads) in the deep stroma (SSCM: Confoscan 4). Reproduced with permission from Werner et al. ${ }^{42}$

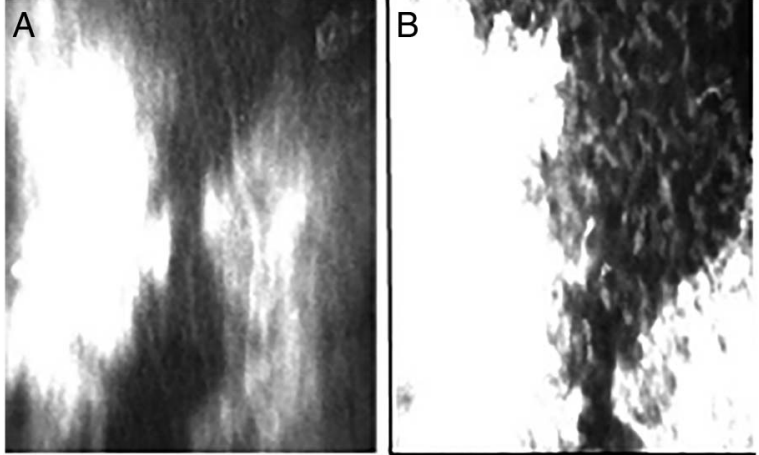

Figure 23 Avellino corneal dystrophy. (A) Focal deposits of highly reflective material with irregular edges in basal epithelium (slit scanning confocal microscopy (SSCM): Confoscan 4). (B) Clusters of highly reflective granular materials with irregular edges at the level of the superficial and middle stroma (SSCM: Confoscan 4). Reproduced with permission from Park et al. ${ }^{49}$

among extracellular matrices with increased intensities are observed. $^{54}$

Pre-Descemet's membrane corneal dystrophy

Anterior stroma of patients with pre-Descemet's membrane corneal dystrophy shows normal keratocyte nuclei and a few irregular highly reflective particles as seen in figure 26A. Posterior stroma in figure 26B reveals hyper-reflective and nonhomogenous structures with numerous tiny inclusions (indicated by arrows). ${ }^{55}$ SSCM (Confoscan 2) was used to capture figure 26A, B.

Posterior amorphous corneal dystrophy

The confocal microscope images of this disease demonstrate microfolds and diffuse hyper-reflective sheet-like opacities with spikes extending from the posterior stroma to the stroma immediately adjacent to the endothelial layer (see figure 27, which was taken by SSCM (Confoscan 3)). ${ }^{56}$

\section{Corneal amyloidosis}

Corneal amyloidosis appears as subepithelial and anterior stromal grey white deposits. The confocal microscopic images show these deposits as intercellular, hyper-reflective, cotton candy-like material, fibrillar amyloid material scattered throughout the anterior stroma as shown in figure 28, which was taken by TSCM. $^{15} 57$

\section{Fungal keratitis}

LSCM is able to reveal numerous hyper-reflective elements resembling Fusarium, Aspergillus hyphae or Candida pseudofilaments in the anterior stroma even in the early phase of fungal keratitis. 158

Fusarium solani reveals numerous highly reflective linear elements (hyphae) of lengths that range between 200 and $300 \mu \mathrm{m}$ and of widths that range between 3 and $5 \mu \mathrm{m}$, with branches at $90^{\circ}$ angles in the anterior stroma as indicated by white arrows in figure 29A. Round inflammatory cells are present also in the stroma as indicated by black arrows in figure 29A, which was taken by LSCM (HRT II-RCM) with field of view $300 \times 300 \mu \mathrm{m}$. Aspergillus hyphae have the same characteristics as Fusarium solani hyphae with branches at $45^{\circ}$ angles. ${ }^{1} 58$

Candida pseudophilaments are characterised by numerous high reflective elongated particles that measure $10-40 \mu \mathrm{m}$ in 

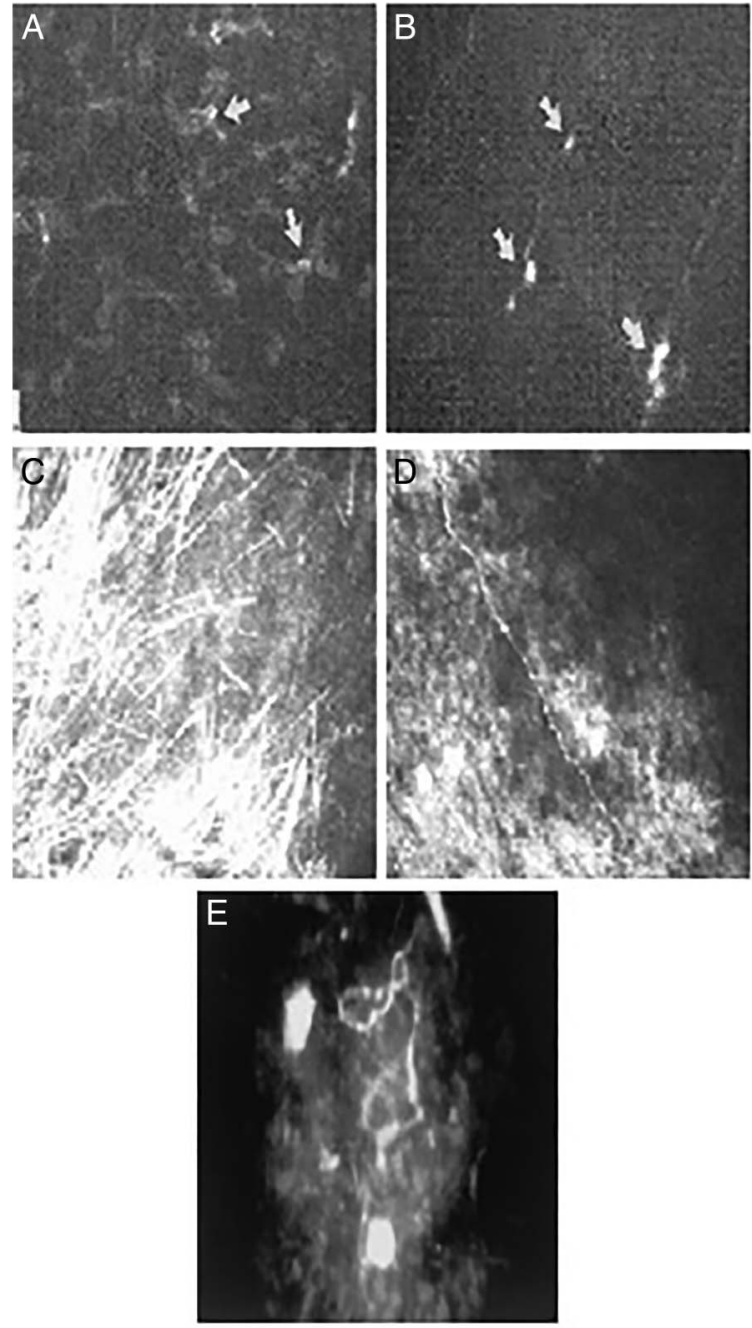

Figure 24 Schnyder crystalline corneal dystrophy. (A) Highly reflective material has accumulated inside and around anterior keratocytes (arrows) (tandem scanning confocal microscopy (TSCM): model 165A). (B) Brightly reflective deposition is associated with the subepithelial nerves (arrows) (TSCM: model 165A). Reproduced with permission from Vesaluoma et $a{ }^{50} .^{5}$ (C) Crystalline deposits with needle shaped appear in the anterior stroma (laser scanning confocal microscopy (LSCM)).

(D) Small number of subepithelial nerves is detectable with high background intensity at the level of Bowman's layer (LSCM).

Reproduced with permission from Kobayashi et al. ${ }^{51}$ (E) Abnormal nerve branches with an irregularly curved appearance in the anterior stroma (slit scanning confocal microscopy: Confoscan 2) Reproduced with permission from Ciancaglini et al. ${ }^{52}$

length and $5-10 \mu \mathrm{m}$ in width located in the anterior stroma as indicated by white arrows in figure $29 \mathrm{~B}$, which was captured by LSCM (HRT II-RCM) with field of view $400 \times 400 \mu$ m. $^{158}$

For easier reference to the appearance of stromal diseases, we summarise the visual signatures of each disease in online supplementary appendix table A3.

\section{Descemet's membrane and endothelial}

Fuchs' endothelial dystrophy (Cornea guttata)

Guttae are characteristic of Fuchs' endothelial dystrophy. At the level of the endothelium, corneal guttae appear in figure $30 \mathrm{~A}$ as roundish hyporeflective areas of varying size with central bright spots and surrounded by hyper-reflective endothelial cells. $^{8} 155960$ TSCM (Topcon SP 2000 P) was used to capture
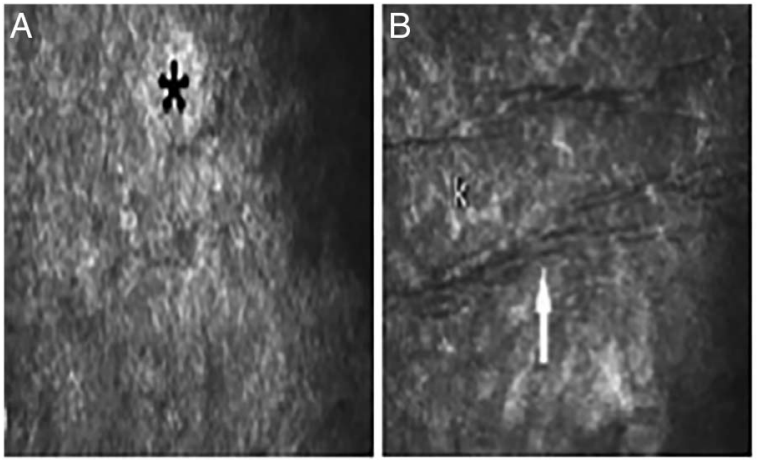

Figure 25 Macular corneal dystrophy. (A) Highly reflective deposits (asterisk) without distinct borders in the superficial stroma (laser scanning confocal microscopy (LSCM): Heidelberg Retina Tomograph II Rostock Cornea Module (HRT II-RCM)). (B) The middle stroma shows homogeneous reflective materials with dark striae-like features (arrow) ( $k=$ keratocytes) (LSCM: HRT II-RCM). Reproduced with permission from Micali et al. ${ }^{53}$

figure 30A. Descemet's membrane displays significant fibrosis in figure 30B, which was captured by SSCM (Confoscan 2). ${ }^{59}$

\section{Iridocorneal endothelial syndrome}

The endothelium in iridocorneal endothelial (ICE) syndrome displays epithelium-like transformation, with prominent bright nuclei with indistinct cell borders. ${ }^{61}$ The studies in refs. 862 confirm that endothelial cells appear as epithelioid-like cells with irregular borders and non-homogenous, diversely shaped nuclei as shown in figure 31. It is worth mentioning here that eyes with ICE syndrome also have some degree of iris atrophy. ${ }^{61}$ SSCM was used to capture figure 31 .

\section{Posterior polymorphous corneal dystrophy}

Vesicles are observed at the level of endothelium in posterior polymorphous corneal dystrophy and appear as relatively big, and well-delineated roundish-shape lesions (having diagonal pattern) containing endothelial cells with surrounding haze, as shown in figure 32A (taken by LSCM (HRT II-RCM) with field of view $400 \times 400$ pixel). They appear as a prominent hyperreflective band lesion at the level of Descemet's membrane, indicated by arrow in figure $32 \mathrm{~B} .{ }^{863}$
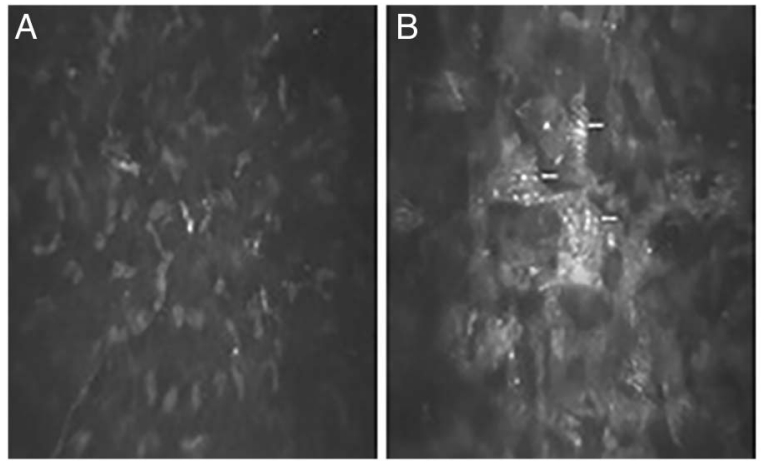

Figure 26 Pre-Descemet's membrane corneal dystrophy. (A) Anterior stroma shows normal keratocyte nuclei and a few irregular highly reflective particles (slit scanning confocal microscopy (SSCM): Confoscan 2). (B) Posterior stroma shows hyper-reflective, non-homogenous structures with numerous tiny inclusions (arrows) (SSCM: Confoscan 2). Reproduced with permission from Ye et al. ${ }^{55}$ 


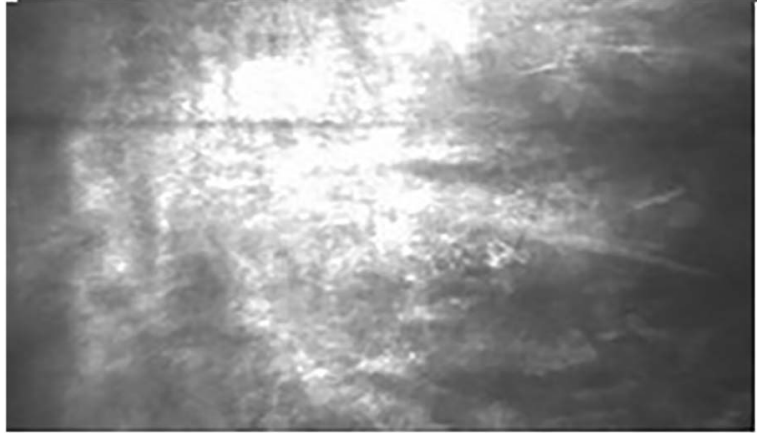

Figure 27 Posterior amorphous corneal dystrophy. Hyper-reflective sheet-like opacities with spikes extending from the posterior stroma (slit scanning confocal microscopy: Confoscan 3). Reproduced with permission from Erdem et al. ${ }^{56}$

A case report in ref. ${ }^{63}$ observes the appearance of endothelial vesicular lesions in curvilinear pattern with associated endothelial pleomorphism and polymegathism (see figure 32C). In patients with more advanced posterior polymorphous dystrophy, very prominent corneal nerves at the level of Bowman's membrane are delineated (see figure 32D). Figure 32B-D were taken by SSCM (Confoscan 2).

\section{Brown-McLean syndrome}

In a Brown-McLean syndrome patient, the stromal structure was masked by the oedema, with no clear outline of the stromal cells (see figure 33A). At the level of the endothelium, pigmentation was observed in figure $33 \mathrm{~B}$ as round, bright, hyperreflective bodies measuring 5-120 $\mu \mathrm{m} .{ }^{64}$ The images of BrownMcLean syndrome were taken by SSCM (Confoscan 2).

For easier reference to the appearance of Descemet's membrane and endothelial diseases, we summarise the visual signatures of each disease in online supplementary appendix table A4.

\section{CONCLUSIONS AND FUTURE WORK}

The cornea has three main layers separated by two thin membranes. The epithelium is the outermost layer separated from the central stromal layer by Bowman's membrane. Descemet's membrane separated stromal layer from the innermost endothelial layer. Each layer and membrane has its distinguished histological structure.

Confocal microscopy is a powerful diagnostic technique that allows non-invasive in vivo cellular imaging of all layers of the

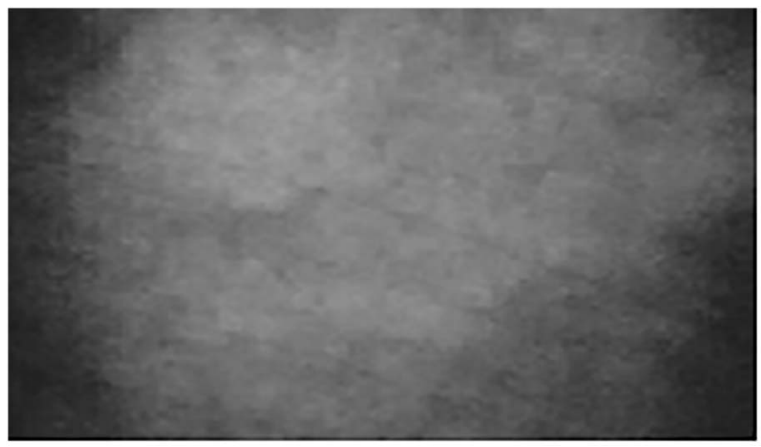

Figure 28 Corneal amyloidosis: subepithelial and anterior stromal grey white, extracellular, hyper-reflective and cotton candy-like deposits (tandem scanning confocal microscopy). Reproduced with permission from Chiou et al. ${ }^{15}$
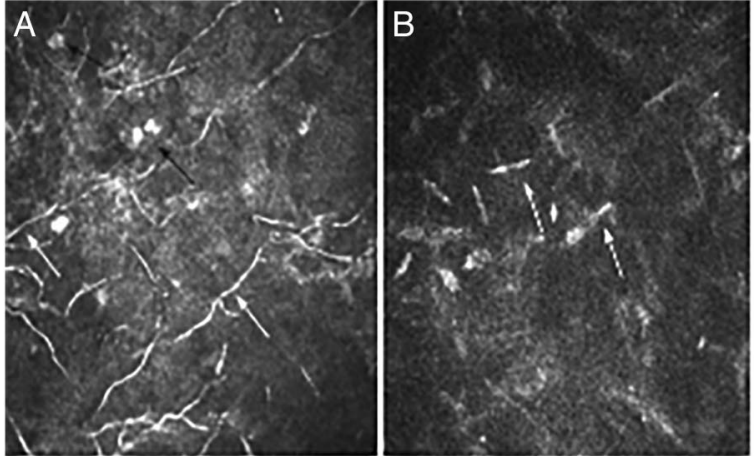

Figure 29 Fungal keratitis. (A) Highly reflective hyphae (Fusarium solani) with branches at $90^{\circ}$ angles in the anterior stroma (white arrows), and round inflammatory cells (black arrows) (laser scanning confocal microscopy (LSCM): Heidelberg Retina Tomograph II Rostock Cornea Module (HRT II-RCM)). (B) High reflective elongated particles (Candida pseudophilaments) in the anterior stroma (white arrows) (LSCM: HRT II-RCM). Reproduced with permission from Brasnu et al..$^{58}$

cornea, enabling the clinical investigation of numerous corneal diseases that are extensive and fall under the areas of corneal dystrophies, degenerations and inflammations. In vivo confocal microscopy is helpful in evaluating the morphological characteristics of corneal abnormalities at the histological level and may be helpful in diagnosis, determination of progression and understanding the pathophysiology of disease. The ability of providing high-resolution images of all layers in the living cornea has enabled new discoveries of corneal pathology at the cellular level.

In this review, we summarise the diagnosis of most common corneal diseases that are typically classified by the layer of the cornea that is affected using IC3D classification, and we have focused on presenting the qualitative changes (visual signature) in the structure and morphology of the involved layer and some parameters of quantitative analysis, especially the reflectivity.

We detected the regions of interest in corneal diseases and extracted their shape-based and grey-level features manually in a step called knowledge base creation, and we categorised these extracted shape-based features of the reviewed diseases into five groups in online supplementary appendixtable B1. This step is going to help us in investigating the edge-and-region-based
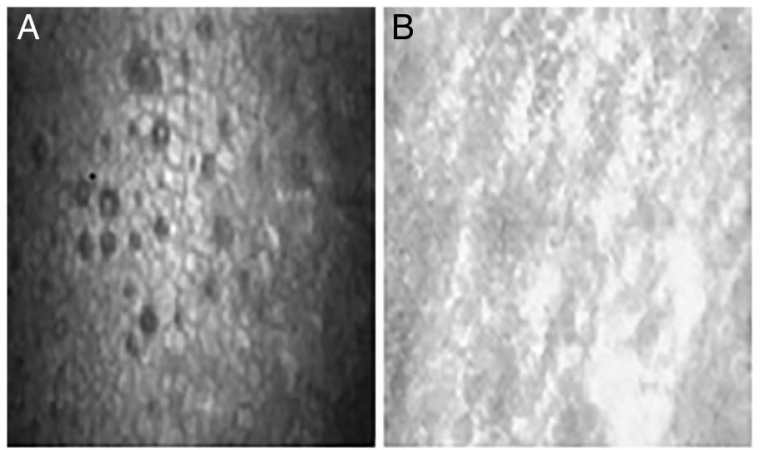

Figure 30 Fuchs' endothelial dystrophy. (A) Roundish hyporeflective areas of varying size surrounded by hyper-reflective endothelial cells (tandem scanning confocal microscopy: Topcon SP 2000 P). Reproduced with permission from Chiou et al. ${ }^{60}$ (B) Descemet's membrane displays significant fibrosis (slit scanning confocal microscopy: Confoscan 2). Reproduced with permission from Grupcheva et al. ${ }^{59}$ 


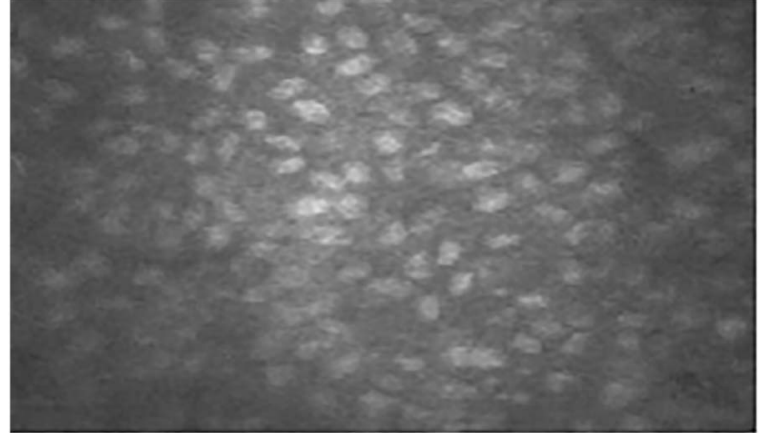

Figure 31 Iridocorneal endothelial syndrome: epithelium-like transformation with prominent bright nuclei, and with irregular and indistinct borders (slit scanning confocal microscopy). Reproduced with permission from Patel and McGhee. ${ }^{62}$

segmentation techniques that are able to detect these regions and then to select the most suitable and effective ones. The next stage is to extract features of the segmented regions; these features give a representative of the information that the image has to offer. We are planning to apply statistical texture-based feature extraction techniques that give feature vectors that will
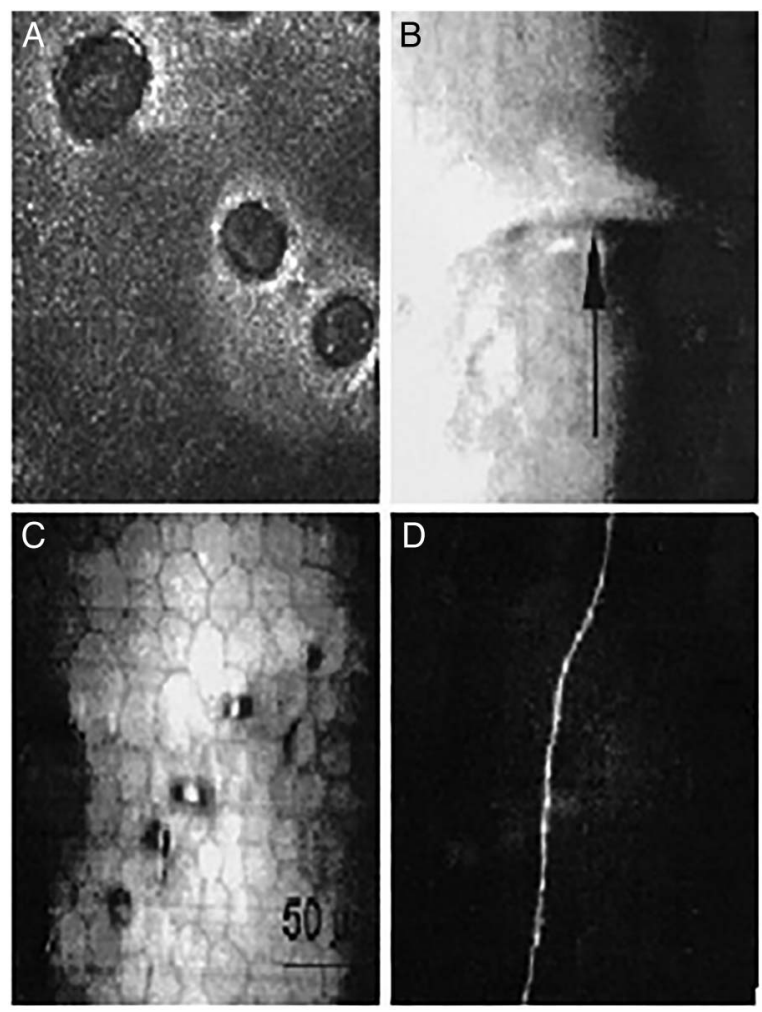

Figure 32 Posterior polymorphous corneal dystrophy. (A) Round lesions containing endothelial cells with surrounding haze (laser scanning confocal microscopy: Heidelberg Retina Tomograph II Rostock Cornea Module (HRT II-RCM)). Reproduced with permission from Niederer and McGhee. ${ }^{8}$ (B) A prominent hyper-reflective band lesion at the level of Descemet's membrane (arrow) (slit scanning confocal microscopy (SSCM): Confoscan 2). (C) Endothelial vesicular lesions in curvilinear pattern with associated endothelial pleomorphism and polymegathism (SSCM: Confoscan 2). (D) Prominent corneal nerves at the level of Bowman's membrane in patient with more advanced posterior polymorphous dystrophy (SSCM: Confoscan 2). Reproduced with permission from Grupcheva et al. ${ }^{63}$

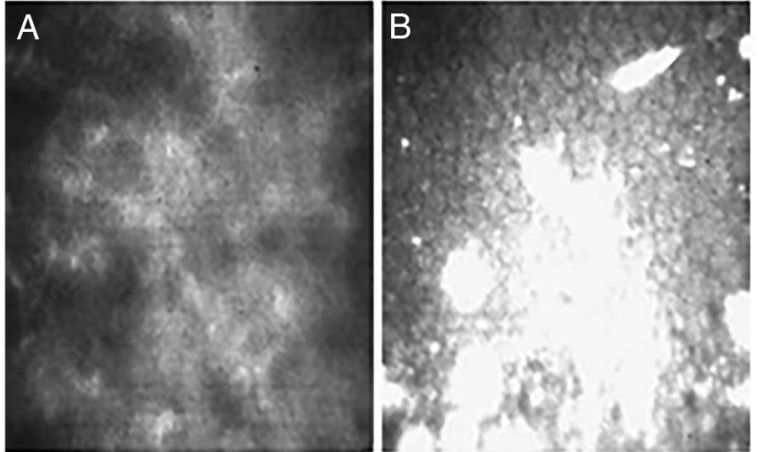

Figure 33 Brown-McLean syndrome. (A) Masked stromal structure with no clear outline of the stromal cells (slit scanning confocal microscopy (SSCM): Confoscan 2). (B) At endothelium, pigmentation appears as round, bright, hyper-reflective bodies (SSCM: Confoscan 2). Reproduced with permission from Vote et al. ${ }^{64}$

be used as input to our classifier aiming to identify the disease that is related to the abnormal cornea. We aim to investigate machine learning approaches to accurately identify the abnormal features of the proposed application.

Put briefly, our aim and future work from this review, as visual computing specialists, is to process the confocal microscopic corneal images and activate appropriate segmentation and feature extraction algorithms to develop an automatic system that can help the ophthalmologists in detecting abnormal cornea and identifying the disease that is related to this abnormality.

Acknowledgements The authors express their gratitude to the following publishers: Elsevier, BMJ, Springer, Wiley, Molecular Vision, Nature and the Korean Ophthalmological Society for giving permission to reproduce images published in their journals, which were used in this study.

Contributors All the authors have contributed equally to the paper, which is written by RA.

Competing interests None declared.

Provenance and peer review Not commissioned; internally peer reviewed.

\section{REFERENCES}

1 Guthoff RF, Zhivov A, Stachs O. In vivo confocal microscopy, an inner vision of the cornea-a major review. Clin Experiment Ophthalmol 2009;37:100-17.

2 Shukla AN, Cruzat A, Hamrah P. Confocal microscopy of corneal dystrophies. Semin Ophthalmol 2012:27:107-16.

3 Tavakoli M, Hossain P, Malik RA. Clinical applications of corneal confocal microscopy. Clin Ophthalmol 2008:2:435-45.

4 Bohnke M, Masters BR. Confocal microscopy of the cornea. Prog Retin Eye Res 1999; 18:553-628.

5 Patel DV, McGhee CN. Quantitative analysis of in vivo confocal microscopy images: a review. Surv Ophthalmol 2013;58:466-75.

6 Hillenaar T. In Vivo Confocal Microscopy expanding horizons in corneal imaging [Ph.D. thesis]. Erasmus University Rotterdam, 2012.

7 Claxton NS, Fellers TJ, Davidson MW. Microscopy, confocal. In: JG Webster, Ed. Encyclopedia of medical devices and instrumentation. John Wiley \& Sons, Inc., 2006, 449-477.

8 Niederer RL, McGhee CNJ. Clinical in vivo confocal microscopy of the human cornea in health and disease. Prog Retin Eye Res 2010;29:30-58.

9 McLaren JW, Nau CB, Kitzmann AS, et al. Keratocyte density: comparison of two confocal microscopes. Eye Contact Lens 2005:31:28-33.

10 Bailly N, Sherif ZA, Pleyer U, et al. [Confocal microscopy in corneal dystrophies: a comparison between confocal slit scanning (ConfoScan P2) and laser scanning microscopy (Rostock Cornea Modul-HRT II)]. Klin Monbl Augenheilkd 2006;223:735-42.

11 Szaflik JP. Comparison of in vivo confocal microscopy of human cornea by white light scanning slit and laser scanning systems. Cornea 2007:438-45.

12 Niederer RL. Assessing the role of the corneal nerve plexus and related microstructural elements in inherited and acquired corneal disease [Ph.D. thesis]. Department of Ophthalmology, University of Auckland, 2008. 
13 Erie EA, McLaren JW, Kittleson KM, et al. Corneal subbasal nerve density: a comparison of two confocal microscopes. Eye Contact Lens 2008:34:322-5.

14 Tomii S, Kinoshita S. Observations of human corneal epithelium by tandem scanning confocal microscope. Scanning 1994;16:305-6.

15 Chiou AG, Kaufman SC, Kaufman HE, et al. Clinical corneal confocal microscopy. Surv Ophthalmol 2006;51:482-500.

16 Tervo T, Moilanen J. In vivo confocal microscopy for evaluation of wound healing following corneal refractive surgery. Prog Retin Eye Res 2003;22:339-58.

17 Jalbert I, Stapleton F, Papas E, et al. In vivo confocal microscopy of the human cornea. Br J Ophthalmol 2003;87:225-36.

18 Miri A, Al-Aqaba M, Otri AM, et al. In vivo confocal microscopic features of normal limbus. Br J Ophthalmol 2012;96:530-6.

19 Petroll WM, Robertson DM. In vivo confocal microscopy of the cornea: new developments in image acquisition, reconstruction, and analysis using the HRT-rostock corneal module. Ocular Surface 2015;13:187-203.

20 Patel DV, McGhee CNJ. In vivo confocal microscopy of human corneal nerves in health, in ocular and systemic disease, and following corneal surgery: a review. Br J Ophthalmol 2009;93:853-60.

21 Miri $A$, Alomar T, Nubile $M$, et al. In vivo confocal microscopic findings in patients with limbal stem cell deficiency. Br J Ophthalmol 2012;96:523-9.

22 Visser N, McGhee CNJ, Patel DV. Laser-scanning in vivo confocal microscopy reveals two morphologically distinct populations of stromal nerves in normal human corneas. Br J Ophthalmol 2009;93:506-9.

23 Weiss JS, Møller HU, Lisch W, et al. The IC3D classification of the corneal dystrophies. Cornea 2008;27:S1-83.

24 Falke K, Buttner A, Schittkowski M, et al. The microstructure of cornea verticillata in Fabry disease and amiodarone-induced keratopathy: a confocal laser-scanning microscopy study. Graefes Arch Clin Exp Ophthalmol 2009;247:523-34.

25 Chiou AY, Kaufman SC, Beuerman RW, et al. A confocal microscopic study of advancing wavelike epitheliopathy. Arch Ophthalmol 1999;117:123-4.

26 Hernandez-Quintela E, Mayer F, Dighiero P, et al. Confocal microscopy of cystic disorders of the corneal epithelium. Ophthalmology 1998;105:631-6.

$27 \mathrm{Ku} J Y$, Grupcheva CN, McGhee CN. Microstructural analysis of Salzmann's nodular degeneration by in vivo confocal microscopy. Clin Experiment Ophthalmol 2002;30:367-8.

28 Roszkowska AM, Aragona P, Spinella R, et al. Morphologic and confocal investigation on Salzmann nodular degeneration of the cornea. Invest Ophthalmol Vis Sci 2011;52:5910-19.

29 Jing Y, Liu C, Wang L. A novel TACSTD2 mutation identified in two Chinese brothers with gelatinous drop-like corneal dystrophy. Mol Vis 2009;15:1580-8.

30 Li J, Qiao J, Cai M, et al. Laser confocal microscopy findings of Thygeson superficial punctate keratitis. Chin Med J (Engl) 2014;127:597-8.

31 Cheng LL, Young AL, Wong AK, et al. In vivo confocal microscopy of Thygeson's superficial punctate keratitis. Clin Experiment Ophthalmol 2004;32:325-7.

32 Steger B, Speicher L, Schmid E, et al. Reversible presence of corpuscular mature dendritic cells in Thygeson's superficial punctate keratitis. Spektrum der Augenheilkunde 2012;26:15-18.

33 Steger B, Speicher L, Philipp W. In-vivo confocal observation of giant dendritic cells in Thygeson's superficial punctate keratitis. Spektrum der Augenheilkunde 2010;24:340-2.

34 Pfister DR, Cameron JD, Krachmer JH, et al. Confocal microscopy findings of Acanthamoeba keratitis. Am J Ophthalmol 1996;121:119-28.

35 Kobayashi A, Ishibashi Y, Oikawa Y, et al. In vivo and ex vivo laser confocal microscopy findings in patients with early-stage acanthamoeba keratitis. Cornea 2008:439-45.

36 Labbe A, Khammari C, Dupas B, et al. Contribution of in vivo confocal microscopy to the diagnosis and management of infectious keratitis. Ocul Surf 2009;7:41-52.

37 Müller RT, Abedi F, Cruzat A, et al. Degeneration and regeneration of subbasa corneal nerves after infectious keratitis: a longitudinal in vivo confocal microscopy study. Ophthalmology 2015;122:2200-9.

38 Vaddavalli PK, Garg P, Sharma S, et al. Confocal microscopy for Nocardia keratitis. Ophthalmology 2006:113:1645-50.

39 Hamrah P, Sahin A, Dastjerdi MH, et al. Cellular changes of the corneal epithelium and stroma in herpes simplex keratitis: an in vivo confocal microscopy study. Ophthalmology 2012:19:1791-7.
40 Hillenaar T, Weenen C, Wubbels RJ, et al. Endothelial involvement in herpes simplex virus keratitis: an in vivo confocal microscopy study. Ophthalmology 2009;116:2077-86.e1-2

41 Rosenberg ME, Tervo TM, Muller LJ, et al. In vivo confocal microscopy after herpes keratitis. Cornea 2002;21:265-9.

42 Werner LP, Werner L, Dighiero P, et al. Confocal microscopy in Bowman and stromal corneal dystrophies. Ophthalmology 1999;106:1697-704.

43 Kobayashi A, Sugiyama K. In vivo laser confocal microscopy findings for Bowman's layer dystrophies (Thiel-Behnke and Reis-Bucklers corneal dystrophies). Ophthalmology 2007;114:69-75.

44 Chiou AG, Beuerman RW, Kaufman SC, et al. Confocal microscopy in lattice cornea dystrophy. Graefes Arch Clin Exp Ophthalmol 1999;237:697-701.

45 Rosenberg ME, Tervo TM, Gallar J, et al. Corneal morphology and sensitivity in lattice dystrophy type II (familial amyloidosis, Finnish type). Invest Ophthalmol Vis Sci 2001:42:634-41.

46 Kailasanathan A, Maharajan S. In vivo confocal microscopy detects preclinical corneal lattice dystrophy. Eye 2013;27:991-2.

47 Frueh BE, Bohnke M. In vivo confocal microscopy of fleck dystrophy. Cornea 1999:18:658-60

48 Kobayashi A, Fujiki K, Fujimaki T, et al. In vivo laser confocal microscopic findings of corneal stromal dystrophies. Arch Ophthalmol 2007;125:1168-73.

49 Park YM, Kim HY, Lee JS. Confocal microscopic findings of avellino corneal dystrophy according to disease severity. J Korean Ophthalmol Soc 2014;55:361-7.

50 Vesaluoma MH, Linna TU, Sankila EM, et al. In vivo confocal microscopy of a family with Schnyder crystalline corneal dystrophy. Ophthalmology 1999:106:944-51.

51 Kobayashi A, Fujiki K, Murakami A, et al. In vivo laser confocal microscopy findings and mutational analysis for Schnyder's crystalline corneal dystrophy. Ophthalmology 2009;116:1029-37.e1

52 Ciancaglini M, Carpineto P, Doronzo E, et al. Morphological evaluation of Schnyder's central crystalline dystrophy by confocal microscopy before and after phototherapeutic keratectomy. J Cataract Refract Surg 2001;27:1892-5.

53 Micali A, Pisani A, Puzzolo D, et al. Macular corneal dystrophy: in vivo confocal and structural data. Ophthalmology 2014;121:1164-73.

54 Kobayashi A, Sugiyama K, Huang AJ. In vivo confocal microscopy in patients with central cloudy dystrophy of Francois. Arch Ophthalmol 2004;122:1676-9.

55 Ye YF, Yao YF, Zhou P, et al. In vivo confocal microscopy of pre-Descemet's membrane corneal dystrophy. Clin Experiment Ophthalmol 2006;34: 614-6.

56 Erdem U, Muftuoglu 0, Hurmeric V. In vivo confocal microscopy findings in a patient with posterior amorphous corneal dystrophy. Clin Experiment Ophthalmol 2007;35:99-102.

57 Kaufman SC, Beuerman RW, Goldberg D. A new form of primary, localized, corneal amyloidosis: a case report with confocal microscopy. Metab Pediatr Syst Ophthal 1995; 18:1-4

58 Brasnu $E$, Bourcier $T$, Dupas $B$, et al. In vivo confocal microscopy in fungal keratitis. Br J Ophthalmol 2007:91:588-91.

59 Grupcheva CN, Craig JP, Sherwin T, et al. Differential diagnosis of corneal oedema assisted by in vivo confocal microscopy. Clin Experiment Ophthalmol 2001:29:133-7.

60 Chiou AG, Kaufman SC, Beuerman RW, et al. Confocal microscopy in cornea guttata and Fuchs' endothelial dystrophy. Br J Ophthalmol 1999;83:185-9.

61 Grupcheva CN, McGhee CN, Dean S, et al. In vivo confocal microscopic characteristics of iridocorneal endothelial syndrome. Clin Experiment Ophthalmol 2004;32:275-83.

62 Patel DV, McGhee CN. Contemporary in vivo confocal microscopy of the living human cornea using white light and laser scanning techniques: a major review. Clin Exp Ophthalmol 2007;35:71-88.

63 Grupcheva CN, Chew GS, Edwards M, et al. Imaging posterior polymorphous corneal dystrophy by in vivo confocal microscopy. Clin Exp Ophthalmol 2001;29:256-9.

64 Vote BJ, Grupcheva CN, Ormonde SE, et al. In vivo confocal microstructural analysis and surgical management of Brown-Mclean syndrome associated with spontaneous crystalline lens luxation. J Cataract Refract Surg 2003;29:614-18. 